\title{
Life Cycle Assessment of Hot Mix Asphalt Production with Reclaimed Asphalt Pavement in Washington State
}

\author{
Milad Zokaei Ashtiani \\ University of Washington
}

\begin{abstract}
This study is an attempt to create a framework, using best available inventory data, to perform lifecycle assessment (LCA) on asphalt pavement production. In particular, the use of reclaimed asphalt pavement (RAP) as an end-of-life product of deteriorated pavements is under consideration. Following ISO 14000 series standards, the framework constitutes of the four major LCA steps in defining goal and scope, lifecycle inventory analysis, environmental impact assessment, and results interpretation. Three different scenarios in which varying portions of RAP are incorporated into hot mix asphalt production are to be compared. The system boundary of this study is limited to the construction and rehabilitation phases and ignores the vehicular use phase. It was found under this study that since high RAP mixtures require more frequent and aggressive maintenance activities, the overall footprint of asphalt pavements constructed with higher RAP contents is also higher. This would necessitate more efficient design procedures and protocols for mixtures produced with high RAP contents to compensate for their lack of long-term performance.
\end{abstract}

\section{Introduction}

Asphalt pavements contribute to the majority of road surfaces worldwide. Three main components of this composite material are crushed aggregates, asphalt binder, and air. Apart from air, the other two elements are not readily available and must undergo several processes before being laid down on a road. These processes in short consist of material extraction and manipulation, preparation of hot mix asphalt (HMA), construction procedures, maintenance, and disposal or recycling of the out of service product. In addition, transportation of materials is required during many stages.

A variety of raw materials as well as construction techniques and design specifications make the comprehension of the best practices in terms of cost effectiveness and impacts on environment difficult (Mukherjee \& Dylla, 2017). In particular, the use of recycled asphalt pavements (RAP) has become a favorable practice among the road agencies and constructors since it is believed to satisfy what is best known as a sustainable design. Being the most recycled material by weight in the U.S. adds to the importance of understanding how these valuable materials should be utilized efficiently.

Life cycle assessment (LCA) is believed to be a powerful method to differentiate alternatives in terms of their impacts, chiefly on the environment (Chester \& Horvath, 2009a)(Santero, Masanet, \& Horvath, 2011a) (Balaguera, Carvajal, Albertí, \& Palmer, 2018). As described in the International Organization of Standardization (ISO) 14040 and 14044, a complete LCA study includes the i) definition of goal and scope, ii) inventory analysis, iii) impact assessment, and iv) result interpretation.

Several studies have been carried out utilizing the perspective specified in the ISO standard to evaluate and compare different applications in the pavement industry. However, there seems not to be a coherent and unanimously agreed procedure to adapt. It can be also realized from the fact 
that there has not been developed a product category classification (PCR) to treat asphalt pavements yet (Mukherjee \& Dylla, 2017). Previous studies, thus, emphasized either on a case by case basis evaluation of paving projects (Jullien, Monèron, Quaranta, \& Gaillard, 2006)(Weiland \& Muench, 2010) (Giani, Dotelli, Brandini, \& Zampori, 2015) (Anthonissen, Braet, \& Van den bergh, 2015) (Polat \& Bektas, 2015) (Farina, Zanetti, Santagata, \& Blengini, 2016), or reviewed the existing literature to give more insight into what is done and what need to be done (Santero, Masanet, \& Horvath, 2011a)(Santero, Masanet, \& Horvath, 2011b) (Balaguera, Carvajal, Albertí, $\&$ Palmer, 2018). For the purpose of this project, an imaginary pavement design will be proposed first and an LCA would be conducted to compare alternatives through certain environmental impact categories.

The following sections explain in detail how these four major steps are broken down for this project which attempts on comparing three scenarios to use RAP in producing, constructing, maintaining, and demolishing hot mix asphalt.

\section{Goal and Scope}

Federal Highway Administration (FHWA) report, which is prepared based ISO 14040 and 14044) is used in this study as a framework to perform LCA (Harvey, et al., 2015). The intended audience of this research project are mainly students at the ME515 course presented by Professor Joyce Cooper. The result of this study could also be helpful to decision/policy makers within the asphalt industry.

Three asphalt mixture alternatives will be compared in this study. Hot mix asphalt designs that contain $0 \%, 20 \%$, and $40 \%$ RAP are considered for comparison. In addition, life cycle inventory analysis for each individual alternative will be developed which is thought to be useful in interpreting results and to bring an insight into existing literature on the subject. The majority of studies done on this subject utilized attributional (process-based) LCA method and so will this study. Details on the impact categories will be followed in subsequent sections; however, this study would investigate two broad categories of energy consumption and emissions to the environment.

A unique asphalt surface layer design is chosen for this project totaling 10" of asphalt mixture in three lifts: two base course layers 3" in thickness, and one surface course 4" in thickness. Although many of the past studies assumed the addition of RAP has no effect on the longevity of asphalt pavement, in this study this assumption is released. The reality is, addition of RAP into asphalt mixtures jeopardize and alleviates the service life of the pavement. As a result, maintenance and rehabilitation operations are required in shorter time intervals to keep the road surface in good conditions.

Another essential difference in the alternatives considered is the inputs of materials to produce asphalt mixtures. Addition of RAP decreases the need for virgin materials and as a consequence mitigate a great portion of the energy consumption and also emissions released to the environment. However, it should be noted that RAP needs to be processed, screened, and stockpiled at asphalt plants. Moreover, the time and temperature required to gain sufficient workability for mixtures containing higher percentages of RAP could be a game changer.

\subsection{Functional Unit}

To scale the inputs and outputs in every stage of an LCA, a functional unit is needed to define the system under evaluation. A functional unit defines the system in terms of magnitude, duration of service, and the expected quality. There is a discrepancy in the literature on what should be 
chosen as a functional unit for running LCA on pavements. (Balaguera, Carvajal, Albertí, \& Palmer, 2018) provides a list of existing studies confining different aspects of LCA characteristics for researches carried out on pavements. It appears that a good amount of studies used a unit of distance (kilometer, meter, mile), or area (square meter, square yard), or volume (cubic meter, cubic yard) as the functional unit.

In this study, a definition of 'a lane-kilometer of asphalt pavement constructed in 2015 which maintain its durability and smoothness during a service life of 50 years' turns out to be the most appropriate. The location of interest is at Seattle, Washington, with a traffic loading of about 3.5 million equivalent single axle load (ESAL) (Weiland \& Muench, 2010). It is worth noting that to keep the pavement in the desirable quality, a series of maintenance and rehabilitation are required. Preliminary assumptions for rehabilitation practices include milling and filling of the top 2" of the asphalt pavement. The only difference between alternatives in this respect is the time intervals in which the maintenance practices needs to be done: respectively for $0 \%, 20 \%$, and $40 \%$ RAP mixtures, milling and filling will be done in 15, 13, and 10 years after construction.

\subsection{System Boundaries}

Figure 1 schematically summarizes the system boundaries determined to achieve the objectives in this study. Since the goal of this study is to compare three alternatives mentioned earlier, several practices are in common when constructing a road. Such shared characteristics are subgrade stabilization, effect of construction and traffic delay, noise pollution, rolling resistance, albedo effects, lighting, and heat island effect. Furthermore, this study focuses on the construction and maintenance of pavement section of the road and ignores the impacts coming from the use phase, i.e. vehicles' fuel consumption.

There are many unit processes associated with the product system shown in Figure 1 (adopted in part from (Huang, Bird, \& Heidrich, 2009)). Life cycle of each raw material including extraction and processing, electricity and fuel consumption at each stage, asphalt mixture preparation which involves heating up aggregates and liquid asphalt, construction equipment emissions, and several transportations to/from facilities. Cut-off criteria is defined so as to eliminate processes that consume less than $10 \%$ of the total required materials weight. Also, the manufacturing of equipment is not considered which comply with the goal and scope. Table 1 is a summary of the results from a limited list of literature reviews done so far for this study including functional units, analysis periods, and impact categories selected.

\subsection{Allocation Procedures}

When dealing with a co-product resulted from recycling of asphalt pavements (i.e. RAP), the allocation of credits to whom take advantage of this seemingly free material should be specified. Double counting could become an issue if allocation is not considered correctly. To properly account for allocation issues with RAP, and to answer the question that who owns this material and alleviation in emissions that it brings about, an open-loop approach would be taken. In that, it is assumed that the RAP is available through the [local] asphalt plant as a raw material. To close the loop, a unit processes must be considered for removal/demolition, processing, and stockpiling RAP after the service life of the pavement section has reached. Although it is hard to track back the owner of project after full service life (50 years), the emissions associated with RAP preparation would be taken into account in this case.

\subsection{Impact Categories, Data Requirements, Interpretation, and Critical Review}


To evaluate and understand the magnitude and significance of the potential environmental impacts, environmental flows should be translated into certain categories. Classification and characterization of impacts would fall into total energy consumption, global warming potential (GWP), acidification, photochemical ozone formation effects on human health and ecosystem, and particulate matter formation The majority of input data would be extracted from Greenhouse Gases, Regulated Emissions, and Energy Use in Transportation Model (GREET), United States Environmental Protection Agency (EPA) AP-42, and EPA NONROAD Model 2008a. Depending on the response time, data from local resources such as aggregate providers or asphalt plant facilities will be collected as primary data. Other online resources will be added subsequently as this project moves forward.

The final part of this report would include an interpretation of results based on a sensitivity analysis of inputs, data quality requirements stated in ISO 14044, and the application of proposed case study in practice. The methodology explained by (Cooper \& Kahn, 2012)Cooper and Kahn (2012) to assess the data quality based on seven categories. Categories are selected based on ISO 14044 recommendations as: 1) reliability and reproducibility, 2) flow data completeness, 3) temporal coverage, 4) geographical coverage, 5) technological coverage, 6) uncertainty, and 7) precision. Each category is then evaluated to satisfy the requirements of having a score of A or B, with A being the higher quality data.

Table 1 -A short list of literatures with functional unit definitions and impact categories

\begin{tabular}{|c|c|c|c|c|c|c|}
\hline Reference & Location & Functional unit & Goal & \multicolumn{2}{|c|}{ Impact categories } & $\begin{array}{c}\text { Analysis } \\
\text { period }\end{array}$ \\
\hline \multirow{5}{*}{$\begin{array}{l}\text { (Weiland \& } \\
\text { Muench, 2010) }\end{array}$} & \multirow{5}{*}{ us } & \multirow{5}{*}{1 lane mile } & \multirow{5}{*}{ compare HMA, PCC, CSOL } & \multirow{5}{*}{ TRACI } & GWP & \multirow{5}{*}{50 years } \\
\hline & & & & & acidification & \\
\hline & & & & & human health & \\
\hline & & & & & eutrophication & \\
\hline & & & & & $\begin{array}{l}\text { photochemical } \\
\text { smog }\end{array}$ & \\
\hline \multirow{3}{*}{$\begin{array}{l}\text { (Giani, Dotelli, } \\
\text { Brandini, \& } \\
\text { Zampori, 2015) }\end{array}$} & \multirow{3}{*}{ Italy } & \multirow{3}{*}{$1 \mathrm{~km}$ (4 lanes) } & \multirow{3}{*}{$\begin{array}{l}\text { compare HMA w/o RAP, } \\
\text { w/ RAP, WMA, cold in- } \\
\text { place recycling }\end{array}$} & \multirow{3}{*}{$\begin{array}{l}\text { ReCiPe } \\
\text { categories }\end{array}$} & GWP & \multirow{3}{*}{$\begin{array}{l}15 \text { years ( } 5 \\
\text { years } \\
\text { maintenance) }\end{array}$} \\
\hline & & & & & $\begin{array}{l}\text { comulative energy } \\
\text { demand (CED) }\end{array}$ & \\
\hline & & & & & water use & \\
\hline \multirow{6}{*}{$\begin{array}{l}\text { (Polat \& Bektas, } \\
\text { 2015) }\end{array}$} & \multirow{6}{*}{ Turkey } & \multirow{6}{*}{1 ton } & \multirow{6}{*}{$\begin{array}{l}\text { compare three HMA with } \\
\text { different binder content }\end{array}$} & \multirow{6}{*}{ SimaPro } & acidification & \\
\hline & & & & & eutrophication & \\
\hline & & & & & GWP & \\
\hline & & & & & human toxicity & \\
\hline & & & & & $\begin{array}{l}\text { photochemical } \\
\text { oxidation }\end{array}$ & \\
\hline & & & & & \begin{tabular}{|l|} 
abiotic depletion \\
\end{tabular} & \\
\hline \multirow{6}{*}{$\begin{array}{l}\text { (Farina, Zanetti, } \\
\text { Santagata, \& } \\
\text { Blengini, 2016) }\end{array}$} & \multirow{6}{*}{ Italy } & \multirow{6}{*}{$1 \mathrm{~m}$} & \multirow{6}{*}{$\begin{array}{l}\text { Compare HMA scenarios } \\
\text { using crumb rubber } \\
\text { and/or RAP }\end{array}$} & \multirow{6}{*}{ SimaPro } & acidification & \multirow{6}{*}{$\begin{array}{l}18 \text { to } 20 \\
\text { years }\end{array}$} \\
\hline & & & & & eutrophication & \\
\hline & & & & & GWP & \\
\hline & & & & & human toxicity & \\
\hline & & & & & $\begin{array}{l}\text { photochemical } \\
\text { oxidation }\end{array}$ & \\
\hline & & & & & abiotic depletion & \\
\hline \multirow{3}{*}{$\begin{array}{l}\text { (Jullien, Monèron, } \\
\text { Quaranta, \& } \\
\text { Gaillard, 2006) } \\
\end{array}$} & \multirow{3}{*}{ France } & \multirow{3}{*}{\begin{tabular}{|l} 
road section \\
$(3.8 \mathrm{~m} \times 150 \mathrm{~m} \times$ \\
$0.07 \mathrm{~m})$ \\
\end{tabular}} & \multirow{3}{*}{$\begin{array}{l}\text { air emissions from three } \\
\text { HMA laying using } 0,10 \text {, } \\
20,30 \% \text { RAP }\end{array}$} & \multirow{3}{*}{ Measurements } & VOC & \multirow{3}{*}{ - } \\
\hline & & & & & PAH & \\
\hline & & & & & odors & \\
\hline $\begin{array}{l}\text { (Anthonissen, } \\
\text { Braet, \& Van den } \\
\text { bergh, 2015) }\end{array}$ & Belgium & $\begin{array}{l}\text { wearing course } \\
\text { section of } \\
300 \mathrm{~m} \text { in length } \\
\text { and } 6 \mathrm{~m} \text { wide }\end{array}$ & $\begin{array}{l}\text { compare HMA to cold mix } \\
\text { with emulsion and WMA } \\
\text { with two additive types }\end{array}$ & $\begin{array}{l}\text { ReCiPe } \\
\text { categories }\end{array}$ & - & 48 years \\
\hline
\end{tabular}




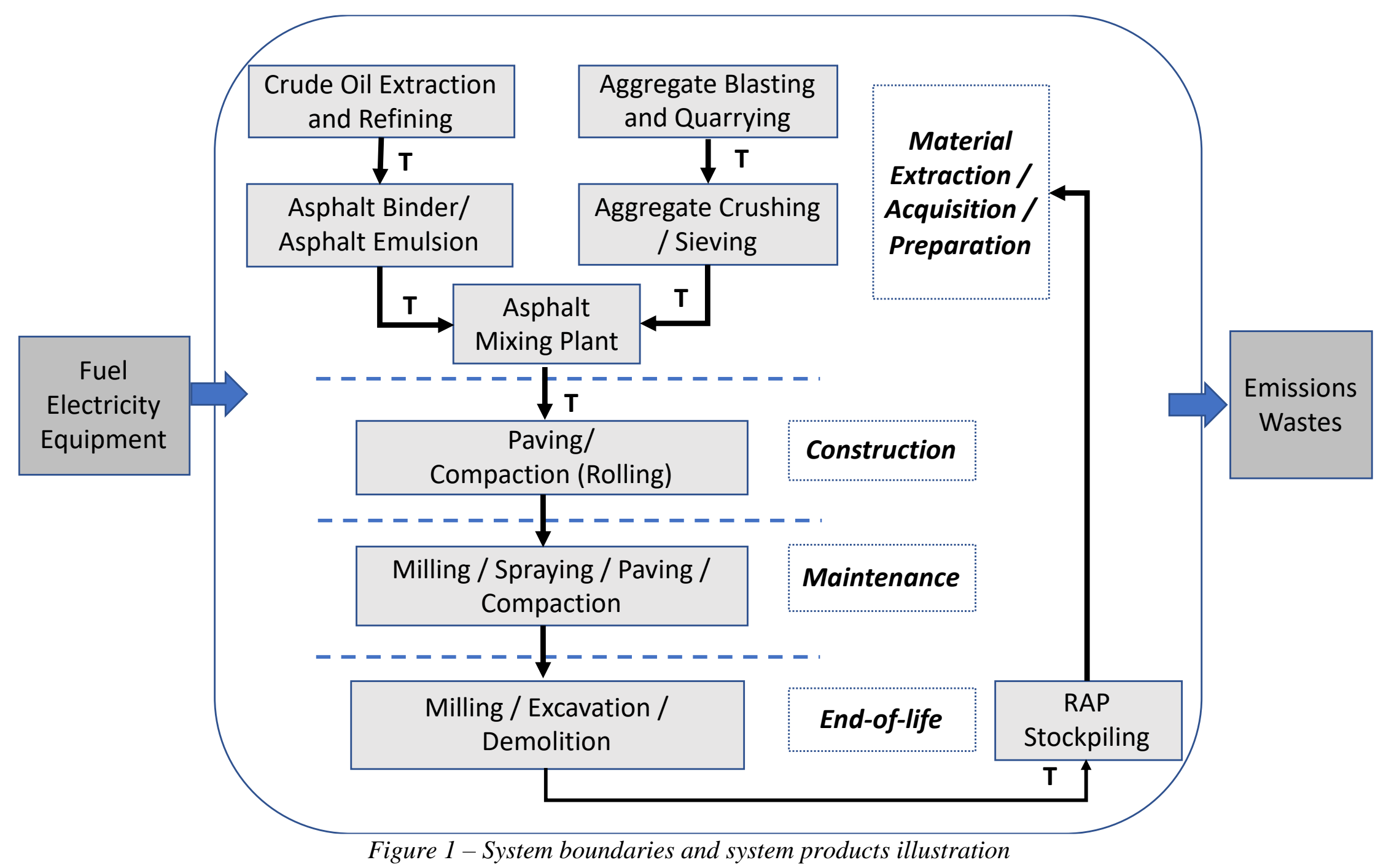


Since this project is intended for learning purposes, the factuality of analysis remains questionable. However, this study attempts at its best to follow the standardized procedure to conduct an LCA. As described in the goal and scope definition, the intended audience of this study will be the students attending the LCA course presented as ME515 in winter 2018. Nevertheless, a critical review of the validity and applicability of results, effect of assumptions and limitations on results, transparency and documentation of data used, and the extent of which data collection procedure satisfies the goal and scope of this study will be discussed.

\section{Inventory Analysis}

The intention of this study was set to compare three different asphalt mixture designs to be used as road surface in a specific route, i.e. along the Interstate-5 in Seattle. These asphalt mixes having different amounts of recycled asphalt pavement are about to be designed with the same thicknesses, and thus same volumes of final product. Reasoning behind this selection is to stick with the definition of functional unit described earlier. However, addition of RAP shortens the life of pavement by endangering its durability. As a result, to end up having a same pavement quality over the lifetime (or equivalently the analysis period) several rehabilitation procedures must be followed to maintain the quality of product.

Figure 2 schematically shows the pavement profile assumed to withstand the traffic condition for this specific location. An assumption has been made that the roadbed is readily available for pavement construction practices. Hence, three lifts of asphalt mixtures will be paved; two 3" and one 4" thick. Rehabilitation is also assumed to include milling of the surface for 2" and paving back an overlay on top of it. Between each lift of asphalt, a layer of emulsified asphalt will be applied to bond each layer to the other.

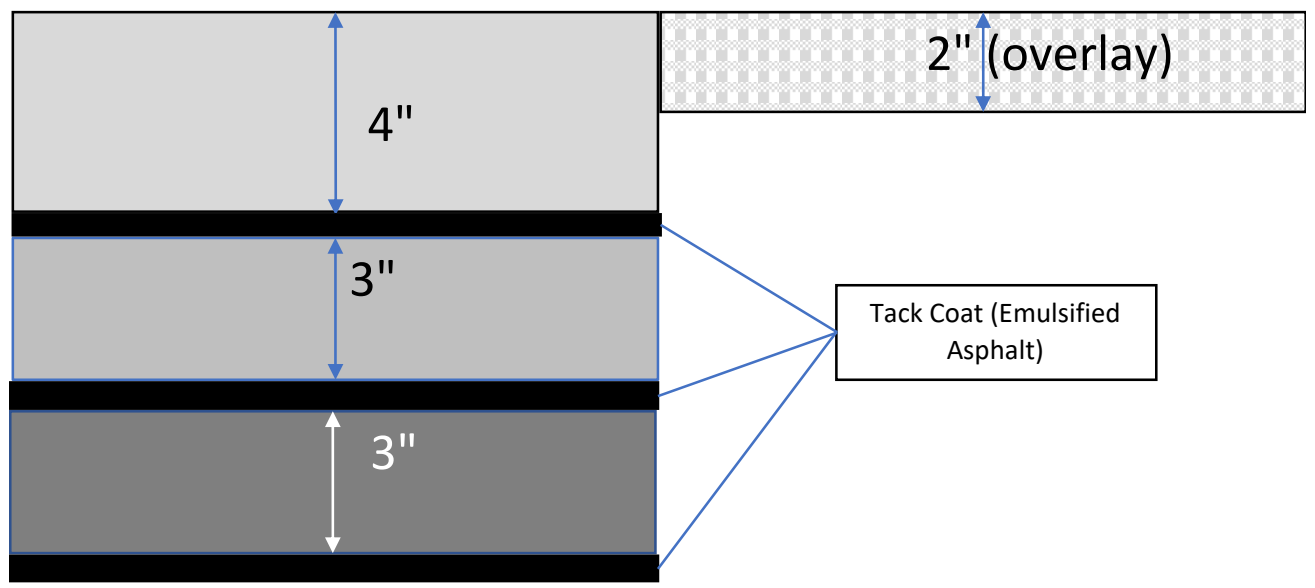

Figure 2 - Proposed pavement profile

\subsection{Reference Flows}

In order to reach the functional unit of this project, several processes are involved within the system boundary defined earlier. In general, these processes are divided into material production, material transportation, and construction practices. Asphalt mixtures consist mainly of stone particles (aka aggregates) and liquid asphalt binder (aka bitumen). Emulsified asphalt binder is used as a tack coat bonding two layers of asphalt mixture together. Transportation phase includes the use of mostly diesel combusting vehicles and considers only the use phase of these vehicles, not the whole life cycle. Construction phase (both initial and subsequent rehabilitations) also 
involves a number of equipment such as paver, roller, material transfer vehicle (MTV), loader, and excavator. Again, this study eliminates the full life cycle analysis of equipment and only considers the use phase.

A final density of $150 \mathrm{lb} / \mathrm{ft}^{3}$ is presumed as the basis to calculate the material requirements. Asphalt binder, sand and gravel stone, and crushed coarse aggregates are assumed to comprise respectively 5.5, 44.5, and 50 percent of the total mass for the designated mixtures. Three alternatives under study contain 0, 20, and 40 percent RAP, assuming that RAP has asphalt binder content of $5.5 \%$ and it consists more of finer aggregate structure. As a result, when using RAP in a mixture, it compensates for $60 \%$ of the sand and gravel and $40 \%$ of crushed stone. It is also worth noting that when RAP is introduced into an asphalt mixture, a higher temperature would be required to maintain appropriate workability during construction. This is in part due to the fact that asphalt binder from RAP is oxidized while was in service. A higher temperature is thus help achieving a certain viscosity in asphalt plant.

On the side of transportation, all the materials are assumed to be carried with a conventional diesel consuming heavy-duty truck running an average speed of 45 miles per hour, each having a capacity of 20 tons. There are four major distances need to be considered for material transportation: i) 50 miles from asphalt plant to construction site, ii) 20 miles from aggregate production site to asphalt plant, iii) 50 miles from project location to dump site (for RAP disposal), and iv) 60 miles from asphalt refinery (located in Tacoma, WA) to asphalt plant. All the distances have been chosen based on the local industries around the Seattle area.

For the construction phase, seven types of vehicles were used as paver (175), material transfer vehicle (300), breakdown roller (175), finish roller (100), excavator (175), loader (175), and HMA milling machine (750), with the numbers in parentheses showing the horsepower. Balancing the production of asphalt (300 tons/hour) with the construction procedure for this specific pavement design will yield to the operation hours required for each piece of equipment to build the road. Tables 2 and 3 are a summary of reference flows required to satisfy the functional unit in this hypothetical project. It should be noted at this point that, the units of measure for reference flows are stated in US format while they will be converted to SI in subsequent sections when solving the inventory problem. The reason is mainly due to the fact that the project is being constructed inside the US, but as the data is chiefly available worldwide with international unit, it has been decided to convert all units to metric within the inventory matrix.

Intervention (environmental) matrix is designed to accomplish the impacts associated with releases of emissions to the environment. Based on the impact categories decided to be studied in this project, 10 flows of emissions been taken into account; namely, sulfur dioxide $\left(\mathrm{SO}_{2}\right)$, volatile organic compounds (VOCs), carbon monoxide $(\mathrm{CO})$, oxides of nitrogen $\left(\mathrm{NO}_{\mathrm{x}}\right)$, particulate matters $\left(\mathrm{PM}_{10}\right.$ and $\left.\mathrm{PM}_{2.5}\right)$, oxides of sulfur $\left(\mathrm{SO}_{\mathrm{x}}\right)$, methane $\left(\mathrm{CH}_{4}\right)$, nitrous oxide $\left(\mathrm{N}_{2} \mathrm{O}\right)$, and carbon dioxide $\left(\mathrm{CO}_{2}\right)$.

\subsection{Unit Processes}

As explained in the reference flows, a number of unit processes involve in accomplishing the goal of this project. Away from the unit processes of construction and material transportation phases which are fairly straight-forward to identify based on the reference flow measurements and estimations, three major processes need more attention. Production of bitumen by refining crude oil, extraction and processing of aggregates, and producing hot mix asphalt in a plant. Other processes consist of electricity generation and production of fuels both for electricity and 
transportation purposes. Process flow charts for bitumen, crushed aggregate, and a batch mix asphalt plant are included in Appendix 8.1 to 8.3., respectively. This study will use other resources life cycle analysis results to evaluate the technology usage and emission generation of these processes. Therefore, a detailed description of each unit process is omitted mainly due to the time restrictions to conclude this project.

\subsection{Data Collection and Assumptions}

A total of 28 unit processes have been defined to achieve the functional unit of building 1 lane$\mathrm{km}$ of pavement. In places where data resources lacked transparency or missed data measures, an attempt has been made to stick with only one resource so as to be consistent. Unit processes have been chosen with an aim to overcome multifunctionality and cut-off in processes. For example, electricity generation utilizes a mix of fuels as input and thus the life cycle of each fuel must be considered in a separate unit process. Or as another example, construction practices involve several stages that use different equipment which call for individually independent unit processes. Data for each category of unit processes were gathered from same sources as a rule of thumb for omitting discrepancies. As a result, four distinct categories were determined to describe unit processes as follows.

\subsubsection{Material Production}

As discussed under previous section, asphalt mixtures consist of aggregates and bitumen. Three sources of information were used to collect data for each type of material. For bitumen (and also emulsion), data were collected from three sources (Weiland, 2008)(Eurobitume, 2012) (Lin, 2012). In assessing their data, feedstock energy was not considered as part of the life cycle since it has been shown in other studies that this might lead to unrealistic impact of bitumen on the life cycle of the whole pavement life cycle (Weiland \& Muench, 2010). A limitation, however, is that most of the data are gathered in Europe and an assumption has been made that the input energy requirements will remain the same in the location under study. Although an electricity mix has been chosen to represent the state of Washington, other fuels types are directly in use as part of refinery facilities.

Life cycle inputs and outputs for aggregate production have been collected mainly from two recourses (PCA, 2007) (Lin, 2012). A local mining site was assumed to produce and process crushed stones, sand, and gravel. Finer aggregate sizes require more energy and emit more emissions in turn. For this reason, coarse aggregate particles assumed to follow the life cycle for crushed stone, and fine aggregates were assumed to stay closer to the life cycle of sand and gravel. Releases to the environment for aggregate and bitumen production lacked an estimation of nitrous oxide and oxides of sulfur other than sulfur dioxide. Also, particulate matters were aggregated into only PM10.

Production of hot mix asphalt in a batch plant also requires remarkable energy and releases emissions mostly to the air. A comprehensive study of more than three hundred asphalt mix plants provides a reliable source for the use of this study (RTI International, 2004). Emission factors were selected based on the assumptions made on the type of plant and fabrics appropriate for this study. In spite of the completeness of this data source and its transparency, the data is somewhat outdated. However, the asphalt mixing technology has not been developed significantly since the date of that study. Asphalt plant was assumed to consume only electricity and natural gas to provide heat and other appliances. Emission factors relating to releases to the air missed data for oxides of sulfur other than sulfur dioxide and nitrous oxide. 
Table 2 - Reference flows for the construction and end of life stage

\begin{tabular}{|c|c|c|c|c|c|}
\hline \multirow[b]{2}{*}{ Phase } & \multirow[b]{2}{*}{ Material/Energy/Functions } & \multirow[b]{2}{*}{ Unit (US) } & \multicolumn{3}{|c|}{ Alternatives } \\
\hline & & & $\begin{array}{l}\text { 0\% } \\
\text { RAP }\end{array}$ & $\begin{array}{l}\mathbf{2 0 \%} \\
\text { RAP }\end{array}$ & $\begin{array}{l}\text { 40\% } \\
\text { RAP }\end{array}$ \\
\hline \multirow{22}{*}{ ن̃ } & Mixing Temperature & Fahrenheit & 310.00 & 320.00 & 330.00 \\
\hline & Total Breakdown Rolling Operation & hours & 6.00 & 8.40 & 10.80 \\
\hline & Total Finisher Rolling Operation & hours & \multicolumn{3}{|c|}{3.00} \\
\hline & Total Paver Operation & hours & \multicolumn{3}{|c|}{11.20} \\
\hline & Number of Paver per lift & item & \multicolumn{3}{|c|}{1.00} \\
\hline & Number of Breakdown Roller per lift & item & 1.00 & 1.00 & 1 or 2 \\
\hline & Number of Finish Roller per lift & item & \multicolumn{3}{|c|}{1.00} \\
\hline & $\begin{array}{l}\text { Additional Energy Use (c=0.92 } \\
\mathrm{kJ} / \mathrm{kg} . \mathrm{K} \text { ) }\end{array}$ & $\mathrm{kJ} /$ tonne & - & 5111.15 & 10217.15 \\
\hline & Breakdown Roller Passes (per lift) & number & 2.00 & 3.00 & 4.00 \\
\hline & Finisher Roller Passes (per lift) & number & 1.00 & 1.00 & 1.00 \\
\hline & Crushed Coarse Stone & ton & 1980.00 & 1679.04 & 1378.08 \\
\hline & Sand and Gravel Stone & ton & 1762.20 & 1310.76 & 859.32 \\
\hline & Asphalt Binder & ton & 217.80 & 178.20 & 138.60 \\
\hline & RAP & ton & 0.00 & 792.00 & 1584.00 \\
\hline & RAP Asphalt & ton & 0.00 & 39.60 & 79.20 \\
\hline & Hot mix asphalt & ton & \multicolumn{3}{|c|}{3960.00} \\
\hline & Emulsified Asphalt Binder & ton & \multicolumn{3}{|c|}{28.04} \\
\hline & Asphalt Transport & ton-mile & \multicolumn{3}{|c|}{198000.00} \\
\hline & Sand and Gravel Transport & ton-mile & 35244.0 & 26215.2 & 17186.4 \\
\hline & Crushed Coarse Stone Transport & ton-mile & 39600.0 & 33580.8 & 27561.6 \\
\hline & Shipping asphalt by truck & ton-mile & 13068.0 & 10692.0 & 8316.0 \\
\hline & Shipping emulsified asphalt by truck & ton-mile & \multicolumn{3}{|c|}{1682.26} \\
\hline \multirow{4}{*}{ 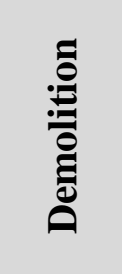 } & Asphalt Milling (900 ton/hr) & hours & \multicolumn{3}{|c|}{4.4} \\
\hline & Backhoe Loader Operation & hours & \multicolumn{3}{|c|}{33} \\
\hline & Excavator Operation & hours & \multicolumn{3}{|c|}{33} \\
\hline & RAP Transport & ton-mile & \multicolumn{3}{|c|}{198000} \\
\hline
\end{tabular}


Table 3 - Reference flows for the maintenance stage

\begin{tabular}{|c|c|c|c|c|c|}
\hline \multirow[b]{2}{*}{ Phase } & \multirow[b]{2}{*}{ Material/Energy/Functions } & \multirow[b]{2}{*}{ Unit (US) } & \multicolumn{3}{|c|}{ Alternatives } \\
\hline & & & $\begin{array}{l}\text { 0\% } \\
\text { RAP }\end{array}$ & $\begin{array}{l}\mathbf{2 0 \%} \\
\text { RAP }\end{array}$ & $\begin{array}{l}\text { 40\% } \\
\text { RAP }\end{array}$ \\
\hline \multirow{28}{*}{ 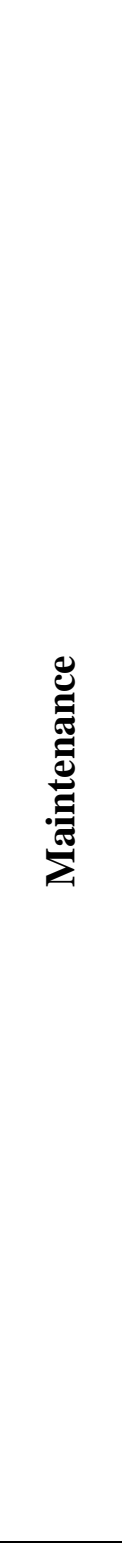 } & Number of Rehabilitations & - & 2 & 3 & 4 \\
\hline & Mixing Temperature & Fahrenheit & \multicolumn{3}{|c|}{310.00} \\
\hline & Total Breaker Operation & hours & \multicolumn{3}{|c|}{1.20} \\
\hline & Total Finisher Operation & hours & \multicolumn{3}{|c|}{1.00} \\
\hline & Total Paver Operation & hours & \multicolumn{3}{|c|}{2.40} \\
\hline & Milling Operation & hours & \multicolumn{3}{|c|}{1.00} \\
\hline & Backhoe Loader Operation & hours & \multicolumn{3}{|c|}{6.60} \\
\hline & Excavator Operation & hours & \multicolumn{3}{|c|}{6.60} \\
\hline & Number of Finisher Roller & item & \multicolumn{3}{|c|}{1.00} \\
\hline & Number of Paver & item & \multicolumn{3}{|c|}{1.00} \\
\hline & $\begin{array}{l}\text { Number of Trucks Trips } \\
\text { (Demolishing) }\end{array}$ & item & \multicolumn{3}{|c|}{39.60} \\
\hline & $\begin{array}{l}\text { Number of Trucks Trips (New } \\
\text { Asphalt) }\end{array}$ & item & \multicolumn{3}{|c|}{39.60} \\
\hline & Number of Excavator (Milling) & item & \multicolumn{3}{|c|}{1.00} \\
\hline & Number of Finisher Passes & number & \multicolumn{3}{|c|}{1.00} \\
\hline & Number of Breaker roller & number & \multicolumn{3}{|c|}{2.00} \\
\hline & Number of Breaker Passes & number & \multirow{2}{*}{\multicolumn{3}{|c|}{1.00}} \\
\hline & Demolished Asphalt & ton & \multirow{2}{*}{\multicolumn{3}{|c|}{$\begin{array}{l}792.00 \\
396.00\end{array}$}} \\
\hline & Crushed Coarse Stone & ton & & & \\
\hline & Sand and Gravel & ton & \multicolumn{3}{|c|}{352.44} \\
\hline & Emulsified Asphalt Binder & ton & \multicolumn{3}{|c|}{18.69} \\
\hline & Asphalt Binder & ton & \multicolumn{3}{|c|}{43.56} \\
\hline & New HMA & ton & \multicolumn{3}{|c|}{792.00} \\
\hline & Transport Demolished Asphalt & ton-mile & \multicolumn{3}{|c|}{39600.00} \\
\hline & Sand and Gravel Transport & ton-mile & \multicolumn{3}{|c|}{7048.80} \\
\hline & Crushed Coarse Stone Transport & ton-mile & \multicolumn{3}{|c|}{7920.00} \\
\hline & Asphalt Transport (FULL) & ton-mile & \multirow{2}{*}{\multicolumn{3}{|c|}{39600.00}} \\
\hline & Asphalt Binder Transport by Truck & ton-mile & & & \\
\hline & $\begin{array}{l}\text { Emulsified Asphalt Transport by } \\
\text { Truck }\end{array}$ & ton-mile & \multicolumn{3}{|c|}{1121.51} \\
\hline
\end{tabular}

A variety of different asphalt mixtures with properties not necessarily close to the case in this project can arise some issues when comparing alternatives considered here (i.e. addition of $20 \%$ and $40 \%$ RAP). An adjustment has therefore been made for asphalt mixtures with RAP using the first law of thermodynamics. By knowing the amount of asphalt mixture used for each alternative, and also using specific heat capacity of $0.92 \mathrm{~kJ} / \mathrm{kg} . \mathrm{K}$ for asphalt mixtures, the additional energy per tons of each mix can be calculated by multiplying heat capacity to the difference in mixing temperature. As an example, for $20 \%$ RAP mixture, it was assumed that mixing temperature would be $320^{\circ} \mathrm{F}$ (in opposed to $310^{\circ}$ for virgin mixture). 


\subsubsection{Material Transportation}

Since local resources are assumed to provide raw materials, transportation of goods will be done only by trucks. A conventional heavy-duty diesel truck from GREET 2015 data base can be a representative of the capacity required for construction purposes. A version of GREET prepared by Professor Cooper (as shown with GREET JSC) was used as a reference for freight transportation vehicles. A breakdown of distances and quantity of material transferred has been tabulated in Tables 2 and 3.

\subsubsection{Initial Construction, Rehabilitation, and End of Life Demolition}

Construction equipment explained in section 3.1. are needed to construct (paving and rolling), rehabilitate (milling, paving, rolling), and demolish (milling) the asphalt pavements. Information on fuel consumptions and efficiencies were gathered originally from NONROAD (2008). However, since NONROAD software encountered some malfunctions due to incompatibility with recent operation systems, data for construction equipment were extracted from elsewhere (Lin, 2012). All equipment was chosen so as to use diesel as fuel. In evaluating the environmental impacts, no data was found on releases of $\mathrm{SO}_{\mathrm{x}}$ and $\mathrm{N}_{2} \mathrm{O}$ for all non-road vehicles. The effect of construction on noise pollution, traffic delay costs, vehicle idling, and transportation of equipment to construction site was considered out of the scope of this study.

\subsubsection{Fuel and Electricity}

Western Electricity Coordinating Council (WECC) region best represents the electricity mix exist in Washington state. GREET JCS 2015 was used to assess the point of use electricity generation input/output as well as for fuel production. A list of fuels considered in this study are i) conventional and LS diesel at fueling station, ii) diesel for construction equipment, iii) natural gas as a stationary fuel, iv) natural gas for electricity generation, v) residual oil at the point of use, and vi) coal to power plant. A flow for non-fossil fuel contribution to electricity was also considered in the intervention matrix. An attributional LCA is intended for use in this study while at the same time rehabilitation practices are planned in the future. To simplify the calculations and avoid extrapolating electricity mix data to future years, only the electricity mix for 2015 was considered.

\subsection{Data Quality, Validation, and Allocation}

Assessment of data quality was carried out based on the seven categories described previously. Although the data quality could be inadequate for a comprehensive analysis of actual design and/or decision making, accomplishing the goal and scope of this study appears reasonable following the evaluation listed in Table 4. Data validation for this project was neglected as for the majority of unit processes a secondary source has been used instead of running the full life cycle. Validation has been performed and discussed in the sources wherever referred. For instance, through bitumen and hot mix asphalt production a mass balance equilibrium was conducted in the original source. Furthermore, the allocation procedure has been discussed prior to this section which attempted on dividing multifunctional unit processes into sub-processes and how data for each individual process was collected.

\subsection{Inventory Problem Solution}

A computational approach described in Heijungs \& Suh (2002) been followed to solve the inventory problem. In that, two separate matrices concerning a technology matrix (A) and an environmental matrix (B) would form the skeleton of an inventory problem. Each row in either 
matrices describes a reference flow and each column is associated with a unit process. A sign convention is to specify energy and material inputs with a negative value, and outputs (releases) to the environment with a positive number. To reach into the functional unit defined for this study, first the technology matrix should be multiplied by a scaling vector (s) to indicate how different unit processes contribute to the inventory problem. Showing mathematically, As=f. A detailed table of technology and environmental matrices are included in Appendix 8.4. Appendix 8.5. also summarizes the resultant scaling vectors.

Solution of an inventory problem, however, requires calculation of the impacts to the environment. An inventory vector (g) is defined in a same way as the functional unit vector. Instead of considering flows in a technology matrix, an inventory vector is built upon how environmental flows of each unit process aggregate into each other. Multiplying the environmental matrix by the scaling vector yields the inventory vector to mathematically satisfy the relation $\mathbf{B s}=\mathbf{g}$. The approach to which this problem can be solved relies on the non-singularity of A matrix. Since the skeleton of the technology matrix in this study was structured to use hollow processes and allocation using sub-processes, a square A resulted in an invertible matrix. As a result; $\mathbf{s}=\mathbf{A}^{-1} \mathbf{f}$, and consequently $\mathbf{g}=\mathbf{B A}^{-1} \mathbf{f}$ would be soluble.

Table 4 - Data quality evaluation following Cooper and Kahn (2012)

\begin{tabular}{|c|c|c|c|c|c|c|c|c|}
\hline \multirow[b]{2}{*}{ Unit Process } & \multirow[b]{2}{*}{ Source } & \multicolumn{7}{|c|}{ Data Quality Category } \\
\hline & & 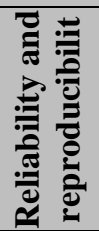 & 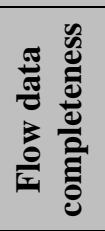 & 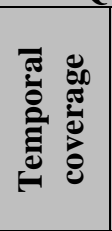 & 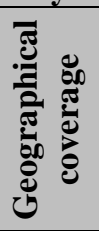 & 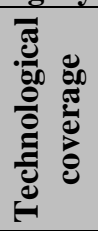 & 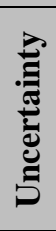 & 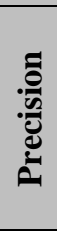 \\
\hline $\begin{array}{l}\text { Bitumen } \\
\text { Production (no } \\
\text { feedstock) }\end{array}$ & $\begin{array}{l}\text { (Lin, 2012), } \\
\text { (Eurobitume, 2012), } \\
\text { (Weiland, } \\
\text { 2008)(Weiland, Life } \\
\text { cycle assessment of } \\
\text { portland cement } \\
\text { concrete interstate } \\
\text { highway rehabilitation } \\
\text { and replacement, 2008) }\end{array}$ & B & $\mathrm{B}$ & B & $\mathrm{B}$ & A & $\mathrm{B}$ & A \\
\hline $\begin{array}{l}\text { Aggregate } \\
\text { Production }\end{array}$ & $\begin{array}{l}\text { (PCA, 2007), (Lin, } \\
\text { 2012), (AP 42, 2004), } \\
(\text { EPA, 2000) }\end{array}$ & B & B & B & B & A & $\mathrm{B}$ & A \\
\hline $\begin{array}{l}\text { HMA } \\
\text { Production }\end{array}$ & $\begin{array}{l}\text { (RTI International, } \\
\text { 2004), (Gillespie, 2012), } \\
\text { (Stripple, 2001) }\end{array}$ & A & A & $\mathrm{B}$ & B & A & A & B \\
\hline $\begin{array}{l}\text { Construction } \\
\text { Equipment }\end{array}$ & $\begin{array}{l}\text { NONROAD 2008, (Lin, } \\
\text { 2012), (Weiland, 2008) }\end{array}$ & A & B & A & A & A & $\mathrm{B}$ & $\mathrm{B}$ \\
\hline Transportation & None (Estimation) & $\mathrm{B}$ & $\mathrm{B}$ & A & A & A & $\mathrm{B}$ & $\mathrm{B}$ \\
\hline $\begin{array}{l}\text { Energy } \\
\text { Generation }\end{array}$ & & B & A & A & A & B & $\mathrm{B}$ & B \\
\hline $\begin{array}{l}\text { Electricity at } \\
\text { POU }\end{array}$ & GREET 2015 (JSC) & A & B & A & A & $\mathrm{B}$ & $\mathrm{B}$ & $\mathrm{B}$ \\
\hline
\end{tabular}




\subsubsection{Inventory Results}

Table 5 summarizes the results of the inventory analysis for this study. The inventory vector for each alternative is compiled with the appropriate number of rehabilitation practices required to fulfill the functional unit. Two major contributors to the environment are the energy consumption from natural resources and the subsequent releases to the environment. Results indicate that although the use of higher RAP contents alleviates the service life of pavement (or equivalently requires more maintenance stages), the overall energy consumption could be up to $30 \%$ lower. The same is also true for each and every emission contributor. With an example of $\mathrm{CO}_{2}$ to be as high as two times for the all virgin asphalt mixture compared to the mix with 40\% RAP. However, a caveat is in order for policy makers as user costs and impacts on traffic is not considered for this study. More maintenance and rehabilitation operations translate into more road closures which in turn imposes both economic and environmental costs.

Considering the whole life-cycle of the three alternatives under study in this project, Figure 3 reveals interesting observations. This chart shows how maintenance and rehabilitation of existing roads can become a game changer in ranking alternatives in terms of energy use. Besides rehabilitation, HMA production, material transport, and bitumen production contribute to more than $85 \%$ of the total energy use for all alternatives. This suggests the importance of considering the maintenance phase of road surface operation in conducting an LCA. Furthermore, as will be discussed later, devising some strategies to perform maintenance operation more efficiently has the ability to change the analysis results remarkably.

Table 5 - Inventory problem solution

\begin{tabular}{|l|c|c|c|c|c|}
\hline \multicolumn{1}{|c|}{ Item } & Unit & 0\% RAP & 20\% RAP & 40\% RAP & Rehabilitation \\
\hline Total Energy & $\mathrm{kJ}$ & $-4.29 \mathrm{E}+09$ & $-4.86 \mathrm{E}+09$ & $-5.43 \mathrm{E}+09$ & $-6.57 \mathrm{E}+08$ \\
\hline Non-Fossil Energy & $\mathrm{kJ}$ & $-8.17 \mathrm{E}+07$ & $-9.03 \mathrm{E}+07$ & $-9.89 \mathrm{E}+07$ & $-1.26 \mathrm{E}+07$ \\
\hline Fossil Fuels & $\mathrm{kJ}$ & $-4.03 \mathrm{E}+09$ & $-4.58 \mathrm{E}+09$ & $-5.12 \mathrm{E}+09$ & $-6.18 \mathrm{E}+08$ \\
\hline Coal & $\mathrm{kJ}$ & $-2.20 \mathrm{E}+08$ & $-2.42 \mathrm{E}+08$ & $-2.64 \mathrm{E}+08$ & $-3.53 \mathrm{E}+07$ \\
\hline Natural Gas & $\mathrm{kJ}$ & $-2.36 \mathrm{E}+09$ & $-2.69 \mathrm{E}+09$ & $-3.01 \mathrm{E}+09$ & $-3.50 \mathrm{E}+08$ \\
\hline Petroleum & $\mathrm{kJ}$ & $-1.45 \mathrm{E}+09$ & $-1.65 \mathrm{E}+09$ & $-1.85 \mathrm{E}+09$ & $-2.33 \mathrm{E}+08$ \\
\hline \hline $\mathrm{SO}_{2}$ & $\mathrm{~g}$ & $2.71 \mathrm{E}+05$ & $2.93 \mathrm{E}+05$ & $3.15 \mathrm{E}+05$ & $4.51 \mathrm{E}+04$ \\
\hline $\mathrm{VOC}^{-10}$ & $\mathrm{~g}$ & $1.44 \mathrm{E}+05$ & $1.57 \mathrm{E}+05$ & $1.71 \mathrm{E}+05$ & $2.36 \mathrm{E}+04$ \\
\hline $\mathrm{CO}^{\mathrm{NO}}$ & $\mathrm{g}$ & $1.43 \mathrm{E}+06$ & $1.63 \mathrm{E}+06$ & $1.82 \mathrm{E}+06$ & $2.17 \mathrm{E}+05$ \\
\hline $\mathrm{NO}_{\mathrm{x}}$ & $\mathrm{g}$ & $5.15 \mathrm{E}+05$ & $5.78 \mathrm{E}+05$ & $6.41 \mathrm{E}+05$ & $8.80 \mathrm{E}+04$ \\
\hline $\mathrm{PM}_{10}$ & $\mathrm{~g}$ & $2.52 \mathrm{E}+05$ & $3.00 \mathrm{E}+05$ & $3.48 \mathrm{E}+05$ & $5.55 \mathrm{E}+04$ \\
\hline $\mathrm{PM}_{2.5}$ & $\mathrm{~g}$ & $3.44 \mathrm{E}+04$ & $4.01 \mathrm{E}+04$ & $4.58 \mathrm{E}+04$ & $5.51 \mathrm{E}+03$ \\
\hline $\mathrm{SO}_{\mathrm{x}}$ & $\mathrm{g}$ & $5.11 \mathrm{E}+04$ & $5.78 \mathrm{E}+04$ & $6.45 \mathrm{E}+04$ & $7.77 \mathrm{E}+03$ \\
\hline $\mathrm{CH}_{4}$ & $\mathrm{~g}$ & $7.23 \mathrm{E}+05$ & $8.13 \mathrm{E}+05$ & $9.03 \mathrm{E}+05$ & $1.11 \mathrm{E}+05$ \\
\hline $\mathrm{N}_{2} \mathrm{O}$ & $\mathrm{g}$ & $2.43 \mathrm{E}+03$ & $2.74 \mathrm{E}+03$ & $3.05 \mathrm{E}+03$ & $3.65 \mathrm{E}+02$ \\
\hline $\mathrm{CO}_{2}$ & $\mathrm{~g}$ & $2.20 \mathrm{E}+08$ & $2.50 \mathrm{E}+08$ & $2.79 \mathrm{E}+08$ & $3.43 \mathrm{E}+07$ \\
\hline
\end{tabular}




\section{Impact Assessment}

Now that the intervention matrix is obtained, it is time to further investigate the effect of each environmental flow on the proposed categories. Following what discussed previously as the goal and scope, this study will investigate how each alternative would affect the environment in terms of a number of impact categories. Impacts are generally classified as having either midpoint or endpoint effects. At the midpoint level, recourse and emissions related impacts form the basis of analysis. The extent of which midpoint categories would spread their influence at lower levels are translated into endpoint categories. The mathematical procedure to achieve midpoint and endpoint contributors involves choosing some characterization factors. The following section describes in more details how inventory results are characterized into the categories of interest in this study.

\subsection{Characterization}

Environmental flows associated with each alternative under study should be translated into more sensible metrics that are concerned with specific environmental phenomenon. A good example is climate change where a combination of emissions contribute in part to its occurrence. Characterization factors are then defined to quantitatively translate emissions and resource extractions to a number of environmental impacts. These factors are obtained from complex models which explanation is out of the scope of this study. There are a number of references that provide these factors, among which ReCiPe is one of the most referred resources. 18 midpoint indicators and 3 endpoint indicators are explained in ReCiPe (Huijbregts, et al., 2016).

Midpoint categories selected for this project are climate change $\left(\mathrm{CO}_{2} \mathrm{eq}\right)$, acidification $\left(\mathrm{SO}_{2} \mathrm{eq}\right)$, photochemical ozone formation (effects on human health and ecosystem, $\mathrm{NO}_{\mathrm{x}} \mathrm{eq}$ ), and particulate matter formation $\left(\mathrm{PM}_{2.5}\right)$. All three endpoint categories of human health (disability adjusted life years or DALY), terrestrial and freshwater ecosystems (species.year) are also considered. The terms stated in parenthesis show the basis each environmental flow is converted to. An individualistic perspective has been adopted wherever that matters. The latest characterization factors were captured from $\underline{\mathrm{ReCiPe}} 2016$ to assess impacts.

As expected, alternatives having more RAP content had the highest impact on the categories under consideration both at midpoint and endpoint levels. As Figures 4 and 5 also suggest, effects are more severe in terms of impacts on climate change (CO2eq) and human health (DALY). Influence on freshwater ecosystem is minimal compared to the rest. However, without a basis for comparison, any conclusion on the significance of each impact category in an overall perspective cannot be made meaningfully. Normalization is a technique to explore in more depth how significant these numbers could be interpreted in a much wider scope.

\subsection{Normalization}

An understanding of how significant the impact assessment results can be in a larger scale (regionally, globally, etc.), normalization attempts on sketching a relation between the emissions produced at the level of this study and a much larger perspective. In other words, although Figure 4 previously showed that the quantity of $\mathrm{CO}_{2} \mathrm{eq}$ is highest compared to other emissions, without knowing the extent of each emissions in a regional scale, drawing a comparison does not seem rational. Hence, since this study was conducted within the Washington state region, some information from reliable data sources will be required for the sake of comparison. The U.S. energy information administration (eia) gathers valuable data on the energy consumption and some of the emissions throughout the country. Reviewing their available databases, information on total energy 
use and production per each source of raw material was found. On the emissions side, $\mathrm{CO}_{2}$ appeared to be the only chemical having a well-documented source of information.

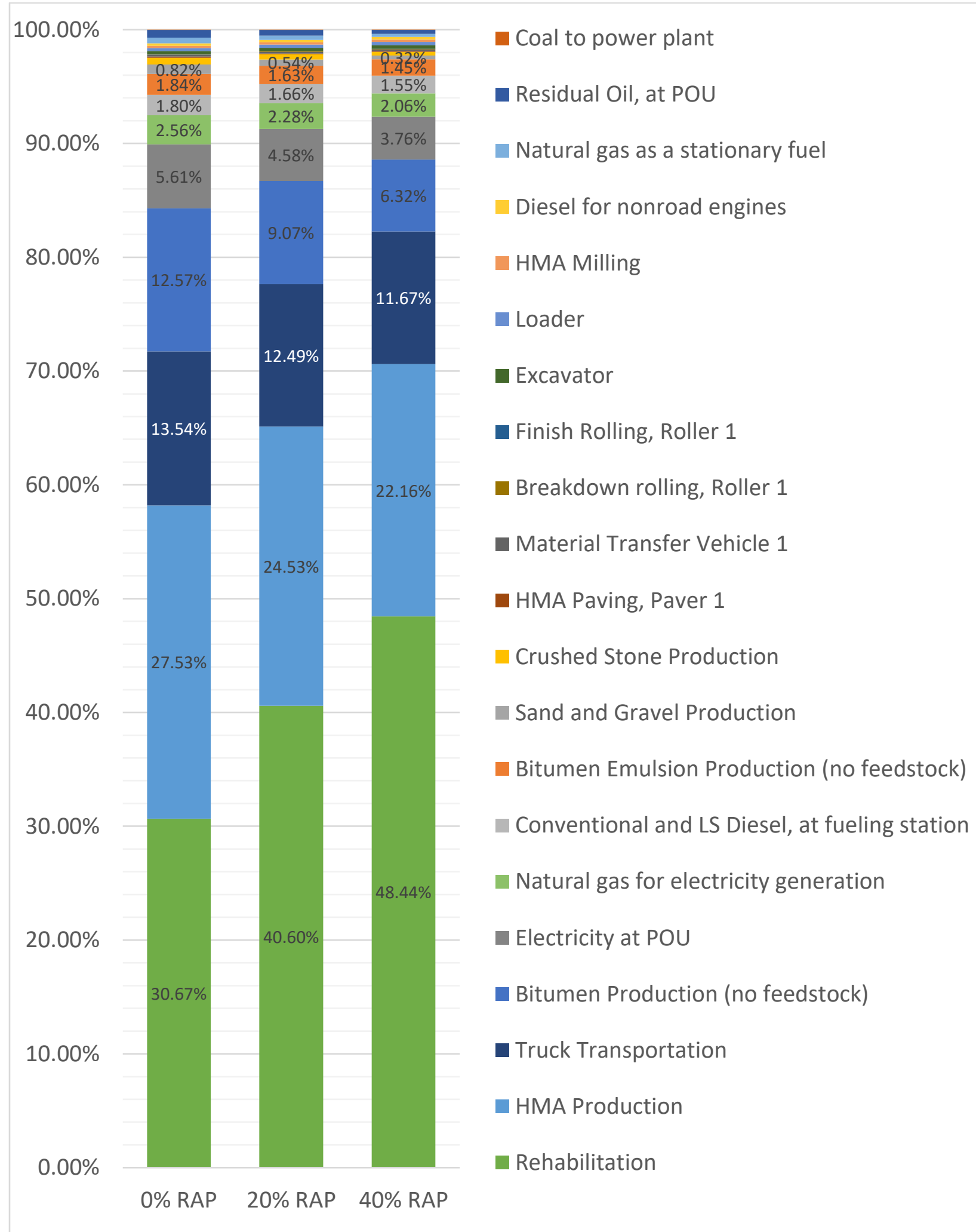

Figure 3 - Life-cycle energy consumption breakdown for each alternative 
State of Washington open data platform also provides valuable information on more detailed emissions throughout the statewide industries under operation. No precise data was existed, however, on their record except for some emissions information for a number of the major facilities within the state. After examining the data from both sources, it has been realized that the $\mathrm{CO}_{2}$ emissions obtained from Washington dataset differs from what eia reports by a factor of four. Since no more reliable dataset was found up to date, a simplistic approach has been followed to make corrections to the state emissions records. In that, all the other emissions were multiplied by a factor of four with the assumption of identical linear correlation among all emissions as for $\mathrm{CO}_{2}$.

Furthermore, the project described in this study is specific to only one lane-mile of pavement construction. There are approximately more than 100,000 lane-miles of road exist in the state of Washington. Based on previous studies, annual statewide hot mix asphalt production falls somewhere near 3.5 million tons. As another estimation, this amount of hot mix asphalt can be translated into nearly 2000 lane-miles of pavement annually constructed with a structure identical to the proposed design in the present research. Multiplying emissions by 2000, then ballparks the amount of emissions produced yearly due to asphalt pavement construction. The ratio of these values to the total statewide emissions are calculated and shown via Figure 6. It is also worth mentioning that in these calculations no rehabilitation was assumed to take place as the data were available only for 2015 .

A surprising immediate observation from Figure 6 is that despite $\mathrm{CO}_{2}$ is produced by more than two orders of magnitude over other emissions (see Table 5), it is not the biggest contributor in a regional scale. Interestingly, particulate matter produced during the initial construction of all alternatives contribute to more than $1.5 \%$ of the total amounts produced annually by major industries within the state. Other noticeable contributor to the total statewide quantities is the natural gas. The reason behind this happening could be that HMA plants consume natural gas as their main source to heat up aggregates and bitumen.

\section{Interpretation}

The last step in conducting an LCA is where data are aggregated, categorized, and are ready for interpretation. Up to this point, results showed that how different alternatives can be sorted out based on some basic measures such as total energy use and their impact on the environment. A conclusion can be made based on the results obtained from inventory analysis and impact assessment. However, the sources of difference have not been recognized in details. This section, therefore, tries to shed more light on the significant issues around each alternative so as to explain which operations during the life cycle of each product dominate the effects on energy and emissions output. Thus, within the subsections that will follow, first the unit processes involved in this project are grouped into certain categories based on their similarities (e.g. transportation, materials production, etc.). A sensitivity of analysis to fluctuations in input values associated with major processes is discussed afterwards. This will help specifying the areas in which improvement in data quality and accuracy is required. Finally, a short discussion on how the results of this study differ from or agree to prior researches carried out through the literature will wrap up the present report. 


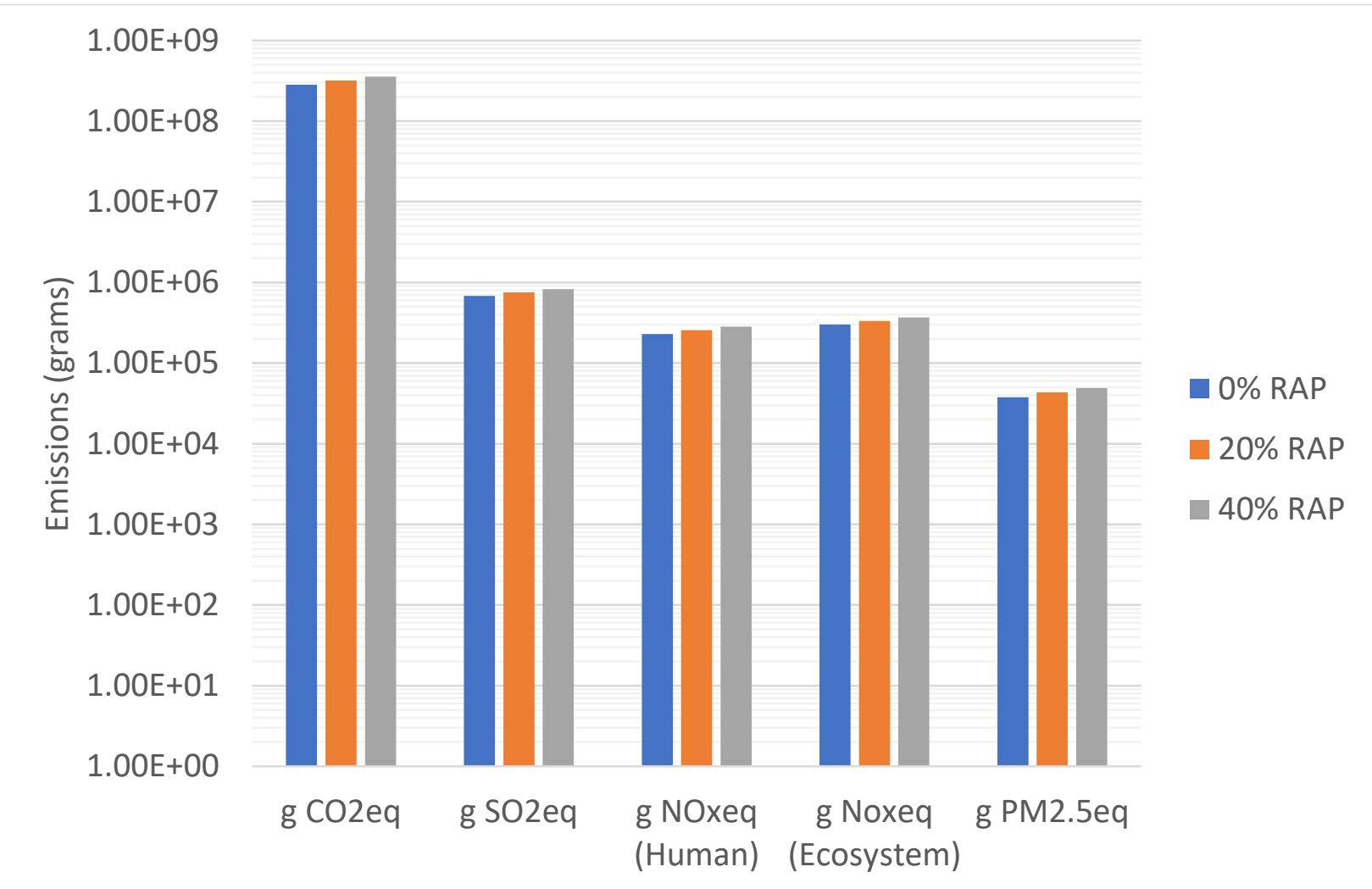

Figure 4 - Midpoint impact assessment

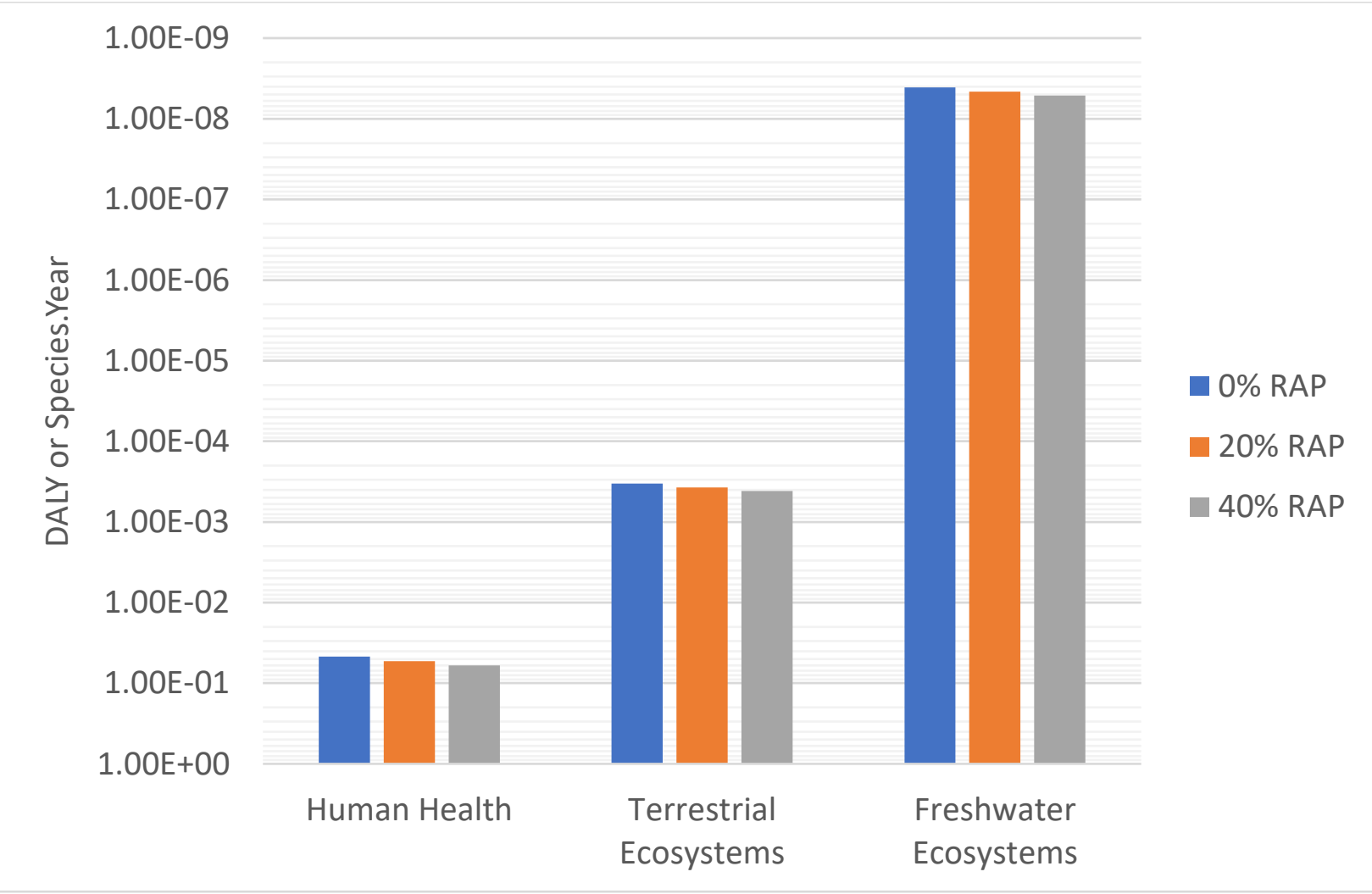

Figure 5 - Endpoint impact assessment 


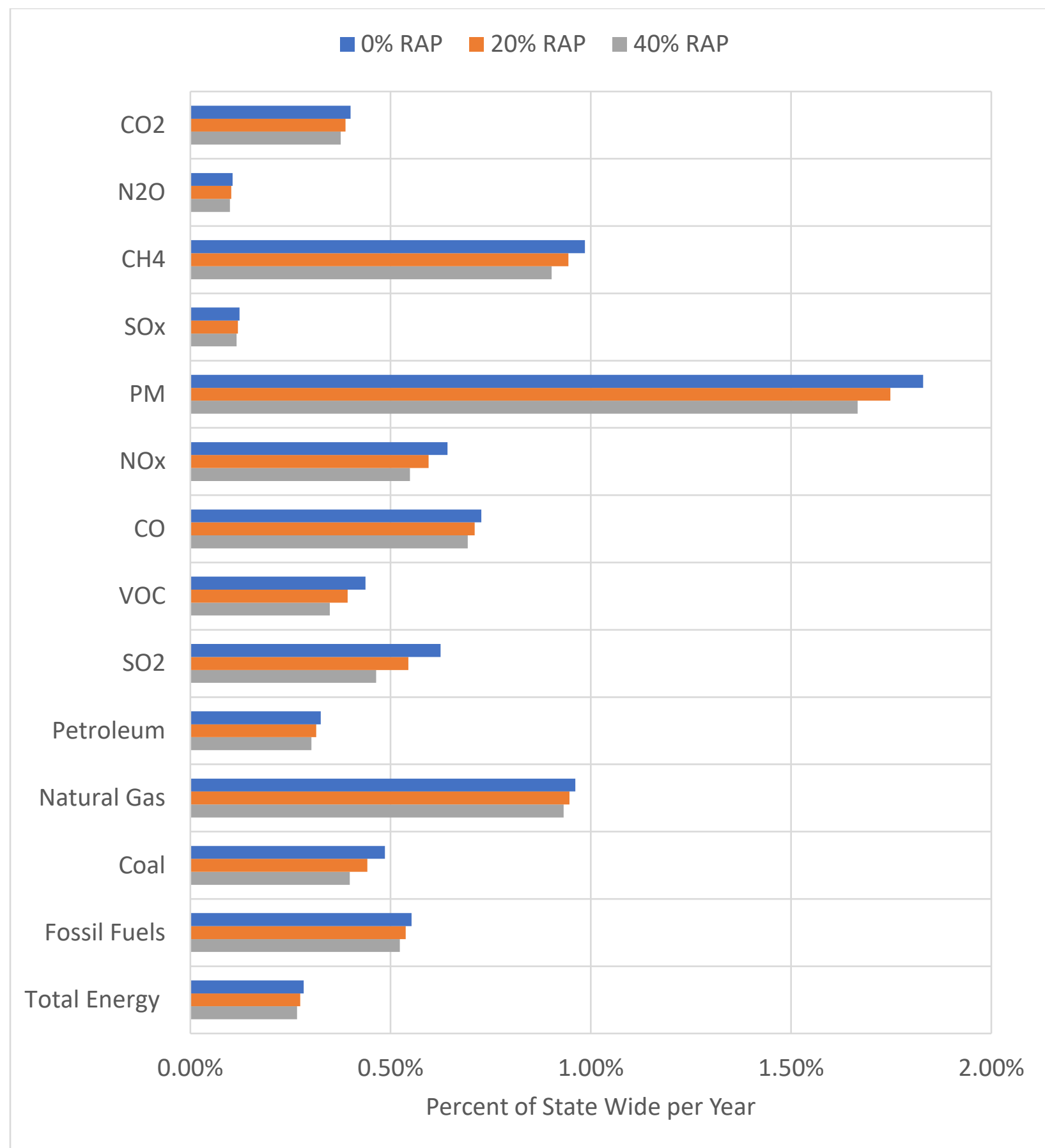

Figure 6 - Statewide normalization results

\subsection{Contribution Analysis}

As mentioned earlier, unit processes defined to fall within the system boundary of this study can be grouped into six major processes. These are defined as i) materials production, ii) material transportation, iii) fuel consumption and electricity generation, iv) end of life demolition, v) initial construction operations, and vi) maintenance and rehabilitation during the analysis period of 50 years. One of the main points of emphasis is the energy consumption. Figure 7 illustrates a breakdown of energy consumption contributed to each group of operation/process. This chart 
explains how material production and lifetime maintenance of roads take up the majority of total energy consumed during the life cycle.

This further suggests that as more RAP is added to asphalt mixtures, maintenance and rehabilitation of pavements become predominant in the amount of energy used to keep road surfaces perform similarly well. Another interesting observation from Figure 7 is that if considering only the first year construction of each alternative, addition of RAP to mixtures lessens the total energy consumption. As a result, one can contend that enhancements in rehabilitation practices can significantly influence how different alternatives are ranked within the total energy use perspective.

Other than energy consumption, it is worthy of mention that how different impact categories contribute to the process groups considered earlier. Figure 8 is one way of allocating each impact category to unit processes for the $0 \%$ RAP alternative, excluding the rehabilitation process. Appendix 8.6. includes a same chart for other two alternatives but the general trend stays almost the same. As can be seen from this chart, materials production again contributes to almost half of all the impacts characterized in this project. Climate change associated with the amount of CO2eq, however, acts quite differently where transportation and fuel/electricity generation together contribute to more than half of the impacts. This could be in part due to the fact that truck transportation has one of the lowest fuel efficiencies among other processes (which also produces high levels of carbon containing emissions). The same interpretation is also true for the fuel consumption especially at the asphalt plant where natural gas is used as one of the primary sources of heat generation.

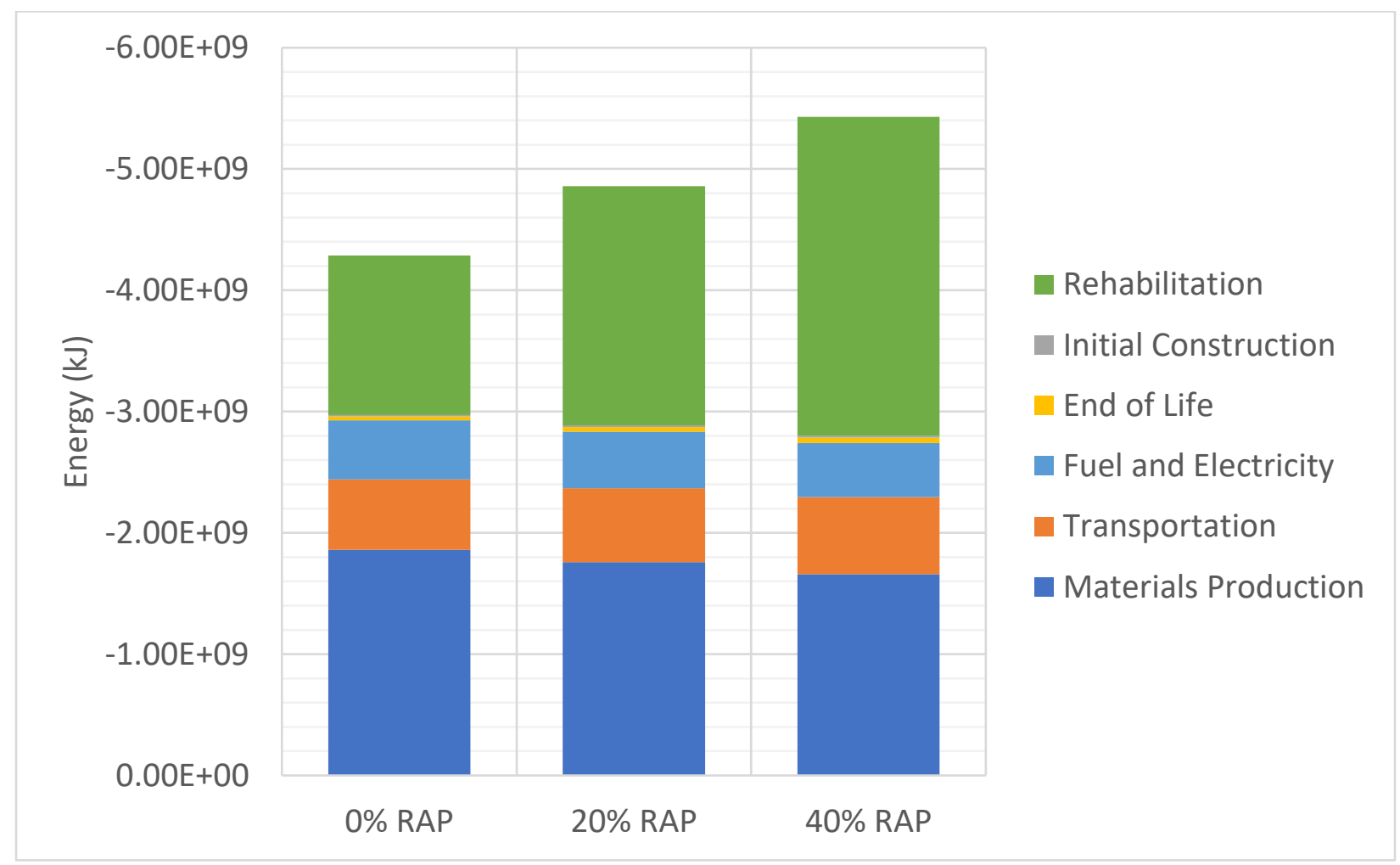

Figure 7 - Energy consumption contribution to groups of unit processes 


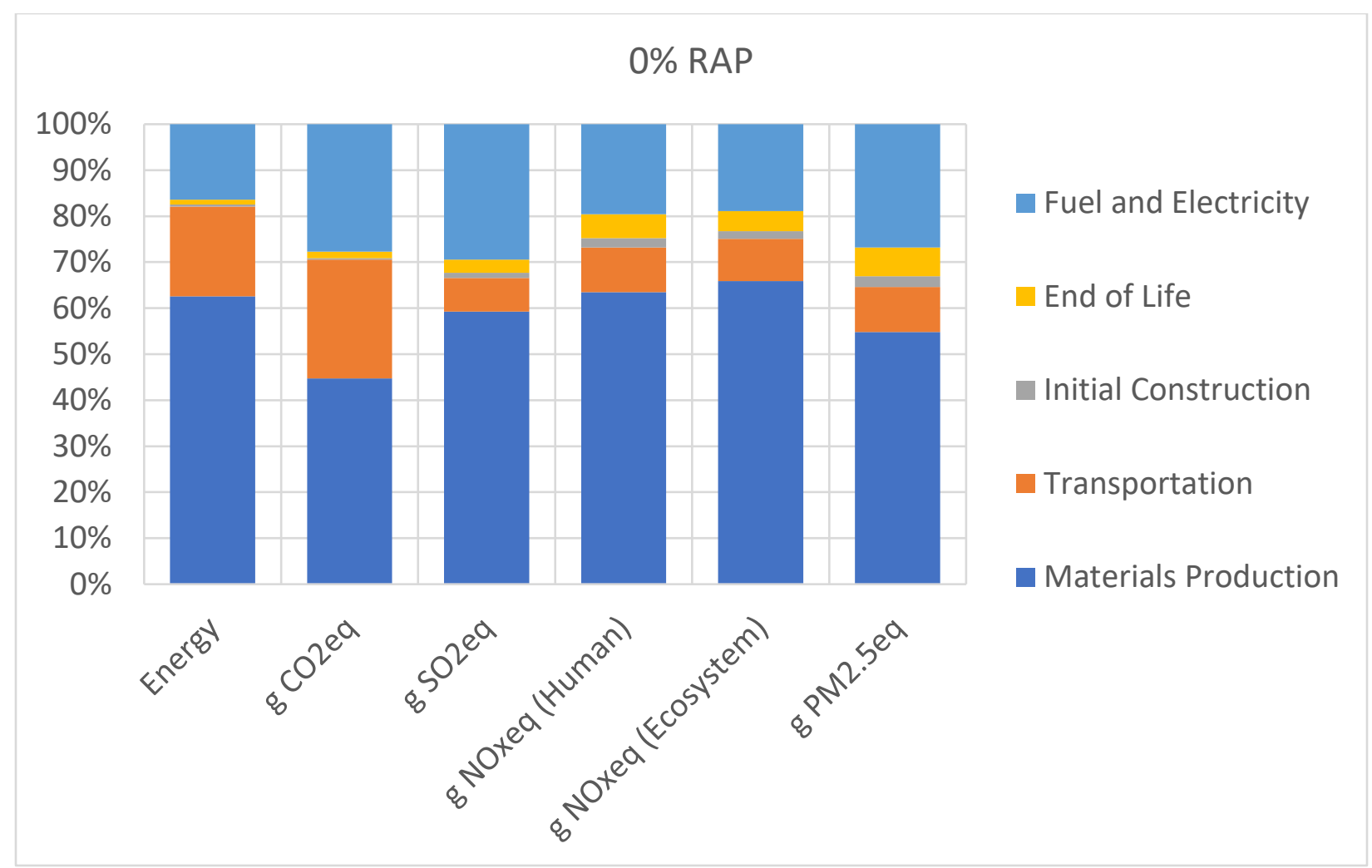

Figure 8-Impact categories contributed to each group of unit processes for the first stage construction of $0 \%$ RAP alternative

\subsection{Sensitivity Analysis}

The previous subsection described how different categorized unit processes contribute to the impacts of interest to this study. Although they are advantageous in specifying which unit processes have the most significant impact in relation to the overall performance of each product, they are unable to show how improving the efficiency of each process can lead to overall better performance of systems as a whole. To this aim, based on the impact of interest which is more critical in an area or a region, decisions can be made to modify and remedy deficiencies associated with certain processes.

Four types of sensitivity analysis are performed to investigate their influence to four impact categories of energy consumption, global warming potential (climate change), acidification, and particulate matter formation. As indicated upon prior sections, three groups of processes (namely materials production, transportation, and rehabilitation) turned out to have the most noticeable influence on the final outcomes. For this reason, the performance of system products were evaluated based on the assumption that each of the can be ameliorated by $20 \%$. To elaborate, truck fuel efficiencies can be improved to produce $20 \%$ less emissions and consume $20 \%$ less energy inputs. HMA and bitumen production can also be amended in a way to consume/produce less energy/emissions. Lastly, a $20 \%$ reduction in rehabilitation effort required during the whole life cycle of each alternative was assumed.

Figure 9 represents the sensitivity analysis results based on each area of enhancement. For all impacts under consideration, more efficient rehabilitation practices rises with the instruction of more RAP into mixtures, which makes sense since rehabilitation was shown to be the major 
contributors to all impact categories. In terms of total energy consumption, higher HMA production efficiency contributes the most with an increase in their effectivity when more RAP is added. In view of the effects on climate change, higher efficiencies in each process would lead to almost similar reduction in $\mathrm{CO} 2 \mathrm{eq}$ emissions. Increasing bitumen production efficiency has the most remarkable impression on acidification. Apparently, higher bitumen production efficiency would impact asphalt mixtures made without RAP as more bitumen is used in products made with only virgin materials. Regarding the particulate matter formation, HMA production again can be viewed as the most significant contributor. Therefore, if for instance an agency concerns more with the particulate matter formation, asphalt plants can be regarded as an essential distributor.

\subsection{Data Evaluation}

Section 5.3. discussed some aspects of data quality collected to run LCA in this project. They were categorized based on an A-B evaluation method where A denoted the case where certain criteria have been met, and B where the opposite is true. Based on what was brought up in previous subsections, major contributors to outputs were identified to be HMA production, bitumen production, transportation, and fuel consumption/electricity generation. Since the rehabilitation process within itself contains no additional base process, a data quality cannot be explained independently for maintenance practices. It is worthwhile now to explore in more details how these major contributors can be qualified as reliable, consistent, and complete sources of data.

\subsubsection{HMA Production}

Data collected for HMA production consists more of "A" quality. Although the data were somewhat outdated, it was based on a comprehensive study of approximately 400 asphalt plants. Since the results were obtained originally from one source (RTI International, 2004), it can be argued that the consistency requirement is met. Being part of the EIA agency, the source of data could also be considered as reliable due to the fact that statistical analysis were performed on their databases. The only deficiency could be related to the inclusion of RAP in their database. Average emission factors have been used to estimate environmental flows in this study where mixtures with and without RAP were aggregated. The data also lacked completeness as $\mathrm{N}_{2} \mathrm{O}$ and $\mathrm{SO}_{\mathrm{x}}$ emissions were not included. This could be a reason why HMA production showed less sensitivity to acidification.

\subsubsection{Bitumen Production}

Data for bitumen production were gathered from a European source which within itself included mostly of "B" quality. One can be skeptical of the geographical coverage more than any other quality category since the bitumen used in this project was assumed to be produced locally near Seattle. The advantage of using one source of data, however, can ascertain to some extent that the data is consistently gathered. One major shortage can be related to environmental flows of $\mathrm{PM}_{2.5}$ formation, $\mathrm{N}_{2} \mathrm{O}$, and $\mathrm{SO}_{\mathrm{x}}$ emissions. As a result, particulate matter formation appeared to be less sensitive to the improvements in bitumen production efficiency. Moreover, $\mathrm{SO}_{\mathrm{x}}$ emissions seem to be included in $\mathrm{SO}_{2}$ since acidification is still sensitive to bitumen production efficiency. 


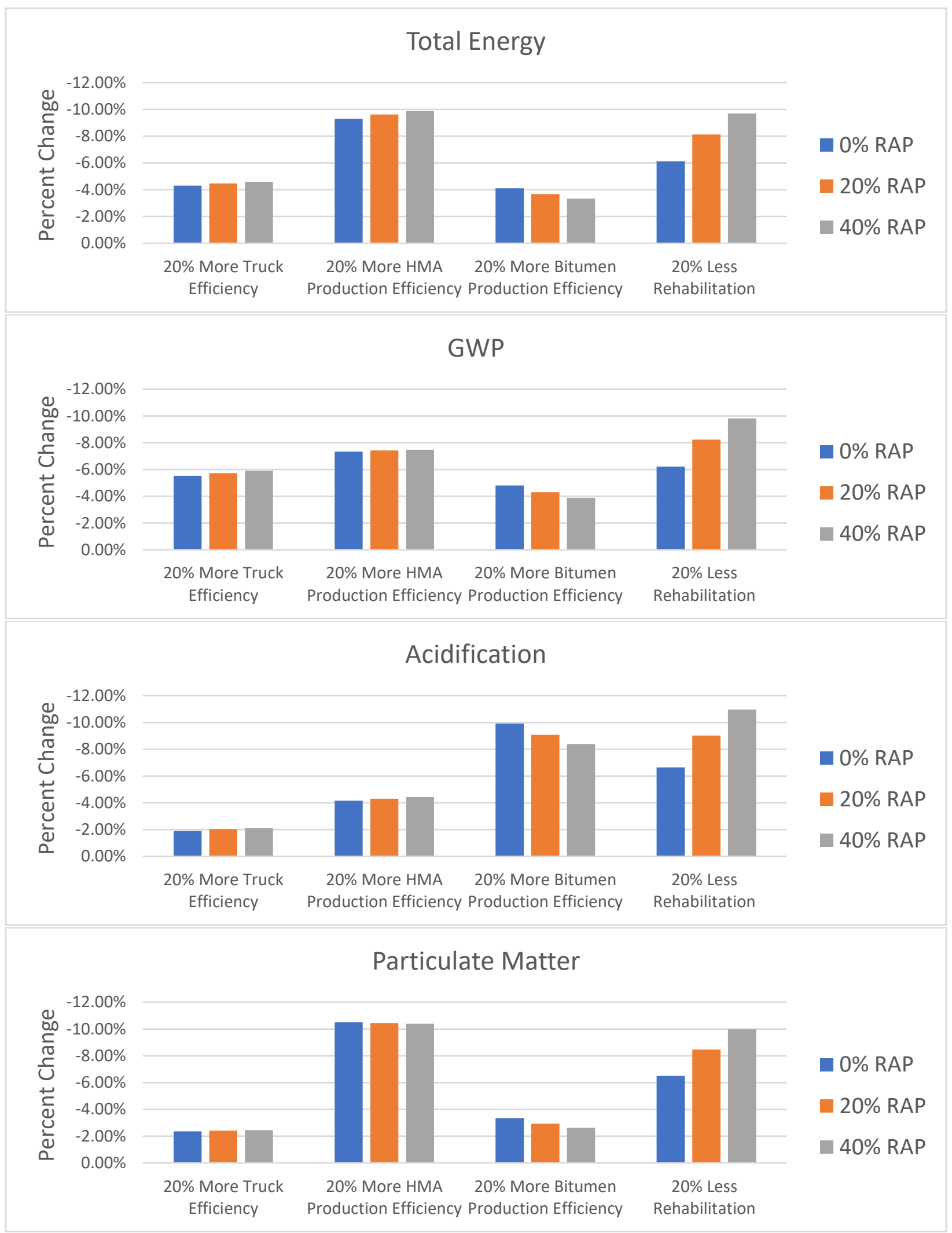

Figure 9 - Sensitivity analysis results based on four different impact categories of energy consumption, climate change, acidification, and particulate matter formation 


\subsubsection{Transportation}

The first thing to note about transportation is that hauling distances are specific to the locations assumed for this project. However, these distances were within a reasonable range for asphalt paving operations and would not differ enormously from site to site. The environmental flows for transportation category, which basically includes fuel consumption and emissions associated with it for a specific type of truck, were extracted from GREET database. The consistency of data is hence subject to a consistent trend and can be thought as being satisfied. Although data quality analysis showed more data having a "B" score, the energy consumption and emissions obtained from GREET seem to be fairly complete except for the evaluation of $\mathrm{SO}_{2}$ releases. To fix this lack of data, an assumption has been made on the equality of $\mathrm{SO}_{\mathrm{x}}$ and $\mathrm{SO}_{2}$ emissions. However, as conferred from the sensitivity analysis discussed earlier, improving transportation efficiency did not contribute significantly to the acidification. More details on RAP transportation efficiency can be found in Ashtiani and Muench (2020).

\subsubsection{Electricity and Energy Generation}

GREET has been used as the primary source of information on the electricity grid and emissions related to energy generation. Since almost every LCA requires data from electricity grid, data in this category seems to be the most reliable. Having the grid grouped into WECC regional electricity is however poses some constraints on the use of data. The state of Washington relies greatly on hydropower for electricity generation, while the same is not true for other states within the region. Same as for transportation data collected from GREET, $\mathrm{SO}_{2}$ releases are not captured as part of the environmental flows. Other than that, GREET seems to provide consistent and complete information on other interventions. A sensitivity analysis was not performed for how enhancing electricity generation efficiency might affect each impact category. The reasoning behind this decision is that it is way more difficult to make short-term adjustments to how electricity grid distributes power and utilizes different sources of energy which is beyond the scope of a unique project.

\subsection{Relation to Other Studies}

Although existing literature seems to have a consistent definition over the functional and functional unit of a piece of road, one challenge in making valid comparisons is the differences in the structural design of road surfaces. This study assumed a 10-inch thick asphalt pavement built in three lifts. It was assumed that (based on experience) this design would last for the analysis period of 50 years. Although having different perspectives into the design details and longevity of pavements, the order of magnitude of the resultant energy consumption and emissions should not differ vastly. No studies to date have addressed the exact problem brought up in this project; compare LCA for alternatives having varying amounts of RAP. The only published paper by Jillien et al. (2006) attempted on comparing pavement layers made with different rates of reclaimed asphalt. They have only gone over the emissions in terms of VOC, polycyclic aromatic hydrocarbon (PAH), and odors and concluded that using RAP might increase these emissions.

The study done by Stripple (2001) is one of the most comprehensive researches on LCA for pavements. The final results for energy consumption and environmental interventions were by one order of magnitude higher for that study. One reason could be due to the fact that soil subbase layers construction also considered in that study. Zaoata and Gambastese (2005) contended that $48 \%$ of energy consumption comes from asphalt mixing and drying of aggregates which is quite higher than what was found in this study (between 40 to $43 \%$ depending on RAP content). They 
further alleged that bitumen production contributes to $40 \%$ of the total energy which is by far different than 19 to $13 \%$ found in this study.

Giani et al. (2015) used a same functional unit as for this project and yielded almost similar results. The order of magnitude for $\mathrm{CO}_{2}$ eq emissions and energy consumption fell in a same range as presented herein. Their results further suggest that extraction and production of virgin materials had up to $40 \%$ contribution to $\mathrm{CO}_{2}$ eq. That study also incorporated the use of RAP in asphalt mixtures and recommended savings of up to $15 \%$ for energy use and emission where RAP is substituted for virgin materials. However, their method included in-place recycling of RAP. Weiland and Muench (2010) have also performed an LCA comparing three different paving alternatives and found that materials production contributes to around half of the total energy and global warming potential. The energy consumption in that study agrees closely to what was found in the present project; however, the $\mathrm{CO}_{2}$ eq emissions are by two order of magnitudes different. This may call for further investigation into their model since the total energy consumptions and global warming potential are closely correlated.

\section{Conclusions and Recommendations}

Recycled asphalt pavements are well known to be the most recycled materials by weight in the U.S. However, using RAP as a substitute for virgin materials endangers the quality of final product which in turn calls for more treatment and preservation practices during its lifetime. This project evaluated the LCA of three major alternatives having no RAP, 20\% RAP, and 40\% RAP for a typical asphalt pavement project in Seattle area. Results of this study showed that impacts associated with using high RAP contents from energy use and emissions releases perspectives are more severe than a mixture made with just virgin materials.

The main contributor to reach this conclusion is the rehabilitation practices required to keep the pavement in acceptable conditions. The other main contributor to all the impact categories is the material production operation, more specifically hot mix asphalt production at plants and bitumen production from crude oil. Based on several assumptions on the extent of pavement works throughout the state of Washington, it was estimated that particulate matter formation contributes to around $1.5 \%$ of total PM emitted by major industries on a yearly basis. Improvements in HMA production has been found to have the most remarkable influence on the final results in terms of energy use and emission.

This study, however, eliminated the use phase of pavements which imposes user costs both from a delay due to traffic point of view and impacts of surface roughness on vehicles' fuel consumption. Both of which would worsen the situation for high RAP content mixtures. On the other hand, the landfilling and processing of RAP was not quite accounted for in this project which might have added some more value to RAP, or equivalently would have decreased the energy consumption/environmental emissions for those mixtures. Although RAP mixtures having more overall energy consumption seemed to be disadvantageous based on the results of this study, there might be more insight into benefits of putting back them into service life which was neglected or ignored. In other words, the extra amount of energy consumption may in fact worth the expenditures (or equally emissions).

To make RAP mixtures win this race, some recommendations could be made on how their use in asphalt mixtures can be amended since rehabilitation turned out to be the main reason those mixtures have lost the competition. One practice is to use closed-loop recycling approach by implementing hot in-place or cold in-place recycling of asphalt mixtures. In this practice, asphalt 
pavement surface is milled out and goes directly to some equipment that heat up the removed RAP right in place. After it has been heated up, adequate amount of virgin materials will be added to meet the mix design requirements. After achieving the proper requirements, they are repaved on the surface and then compacted using some rollers. This practice basically eliminates the processing and transportation of RAP to and from site.

As another suggestion, a softer bitumen is widely believed to compensate for the adverse effects of the aged bitumen coming from out of service RAP. Softer bitumen is less viscous and will help achieving an overall less oxidized blends of aged and virgin bitumen. As a consequence, the number of rehabilitation practices for high RAP contents could become just as the same as all virgin asphalt mixtures. This will greatly widens the service life of mixtures made with RAP. The downside of this approach is primarily related to the additional costs incurred to the contractors. A softer grade of asphalt binder usually costs more than what is required for all virgin mixtures. In terms of energy use and emissions, however, no significant changes are expected to occur for different grades of bitumen.

\section{References}

Anthonissen, J., Braet, J., \& Van den bergh, W. (2015). Life cycle assessment of bituminous pavements produced at various temperatures in the Belgium context. Transportation Research Part D, 41, 306-317.

AP 42. (2004). Introduction to construction and aggregate processing. In Compilation of air emission factors (p. Section 11.19). U.S. Environmental Protection Agency.

Balaguera, A., Carvajal, G. I., Albertí, J., \& Palmer, P. F. (2018). Life cycle assessment of road construction alternative materials: A literature review. Resources, Conservation \& Recycling, 132, 37-48.

Chester, M. V., \& Horvath, A. (2009a). Environmental assessment of passenger transportation should include infrastructure and supply chains. Environmental Research Letters, 4(2), $1-8$.

Cooper, J. S., \& Kahn, E. (2012). Commentary on issues in data quality analysis in life cycle assessment. International Journal of Life Cycle Assessment, 17(4), 499-503.

EPA. (2000). Hot mix asphalt plants emission assessment report. Emissions Monitoring and Analysis Division, Office of Air Quality Planning and Standards. Research Triangle Park, NC: U.S. Environmental Protection Agency.

Eurobitume. (2012). Life cycle inventory: Bitumen. Brussels, Belgium: European Bitumen Association.

Farina, A., Zanetti, M. C., Santagata, E., \& Blengini, G. A. (2016). Life cycle assessment applied to bituminous mixtures containing recycled materials: Crumb rubber and reclaimed asphalt pavement. Resources, Conservation \& Recycling, 117, 204-212.

Giani, M. I., Dotelli, G., Brandini, N., \& Zampori, L. (2015). Comparative life cycle assessment of asphalt pavements using reclaimed asphalt, warm mix technology and cold in-place recycling. Resources, Conservation \& Recycling, 104, 224-238.

Gillespie, I. (2012). Quantifying the energy used in an asphalt coating plant. Department of Mechanical and Aerospace Engineering. University of Strathclyde.

GREET. (2015). The greenhouse gases, regulated emissions, and energy use in transportation model . Retrieved February 2018, from Argonne National Laboratory: https://greet.es.anl.gov 
Harvey, J. T., Meijer, J., Ozer, H., Al-Qadi, I. L., Saboori, A., \& Kendall, A. (2015). Pavement life-cycle assessment framework. Federal Highway Administration (FHWA), U.S. Department of Transportation. Washington, D.C.: FHWA.

Heijungs, R., \& Suh, S. (2002). The computational structure of life cycle assessment (Vol. 11). Kluwer Academic Publishers.

Huang, Y., Bird, R., \& Heidrich, O. (2009). Development of a life cycle assessment tool for construction and maintenance of asphalt pavements. Journal of Cleaner Production, 17, 283-296.

Huijbregts, M. A., Steinmann, Z. J., Elshout, P. M., Stam, G., Verones, F., Vieira, M., .. Zelm, R. (2016, December 12). ReCiPe2016: a harmonised life cycle impact assessment method at midpoint and endpoint level. International Journal of Life Cycle Assessment, $22(2), 138-147$.

IARC. (2013). Bitumens and bitumen emissions, and some $n$ - and s-heterocyclic polycyclic aromatic hydrocarbons (Vol. 103). Lyon, France: International Agency for Research on Cancer.

Jullien, A., Monèron, P., Quaranta, G., \& Gaillard, D. (2006). Air emissions from pavement layers composed of varying rates of reclaimed asphalt. Resources, Conservation \& Recycling, 47, 356-374.

Lin, Y.-Y. (2012). Eco-decision making for pavement construction projects. Department of Civil and Environmental Engineering. Seattle, WA: University of Washington.

Mukherjee, A., \& Dylla, H. (2017). Challenges to using environmental product declarations in communicating life-cycle assessment results. Transportation Research Record: Journal of the Transportation Research Board, 2639, 84-92.

NONROAD. (2008). NONROAD model (nonroad engines, equipment, and vehicles). Retrieved February 2018, from U.S. Environmental Protection Agency: https://www.epa.gov/moves/nonroad-model-nonroad-engines-equipment-and-vehicles

PCA. (2007). Life cycle inventory of portland cement concrete. Sokie, IL: Portland Cement Association.

Polat, M. O., \& Bektas, N. (2015). Life cycle assessment of asphalt pavement product. Journal of Sustainable Environment Resource, 25(5), 275-281.

RTI International. (2004). Emission factor documentation for AP-42; Section 11.1: Hot mix asphalt plants. Office of Air Quality Planning and Standards, Emission Measurement Center. Research Triangle Park, NC: U.S. Environmental Protection Agency.

Santero, N. J., Masanet, E., \& Horvath, A. (2011a). Life-cycle assessment of pavements part I: Critical review. Resources, Conservation \& Recycling, 55, 801-809.

Santero, N. J., Masanet, E., \& Horvath, A. (2011b). Life-cycle assessment of pavements part II: Filling the research gaps. Resources, Conservation \& Recycling, 55, 810-818.

Stripple, H. (2001). Life cycle assessment of road: A pilot study for inventory analysis. Gothenburg, Sweden: IVL Swedish Environmental Research Institute.

Weiland, C. D. (2008). Life cycle assessment of portland cement concrete interstate highway rehabilitation and replacement. Department of Civil and Environmental Engineering. Seattle, WA: University of Washington.

Weiland, C. D., \& Muench, S. T. (2010). Life-cycle assessment of reconstruction options for interstate highway pavement in Seattle, Washington. Transportation Research Record: Journal of the Transportation Research Board, 2170, 18-27. 
Zapata, P., \& Gambatese, J. A. (2005, March 1). Energy consumption of asphalt and reinforced concrete pavement materials and construction. Journal of Infrastructure Systems , 11, 9-20.

Zokaei Ashtiani, M., \& Muench, S. (2020). Network-Level Life Cycle Assessment of Reclaimed Asphalt Pavement in Washington State. International Symposium on Pavement. Roadway, and Bridge Life Cycle Assessment. Sacramento, CA: Taylor \& Francis. doi:10.1201/9781003092278-25

\section{Appendix}




\subsection{Bitumen Production Flow Chart}

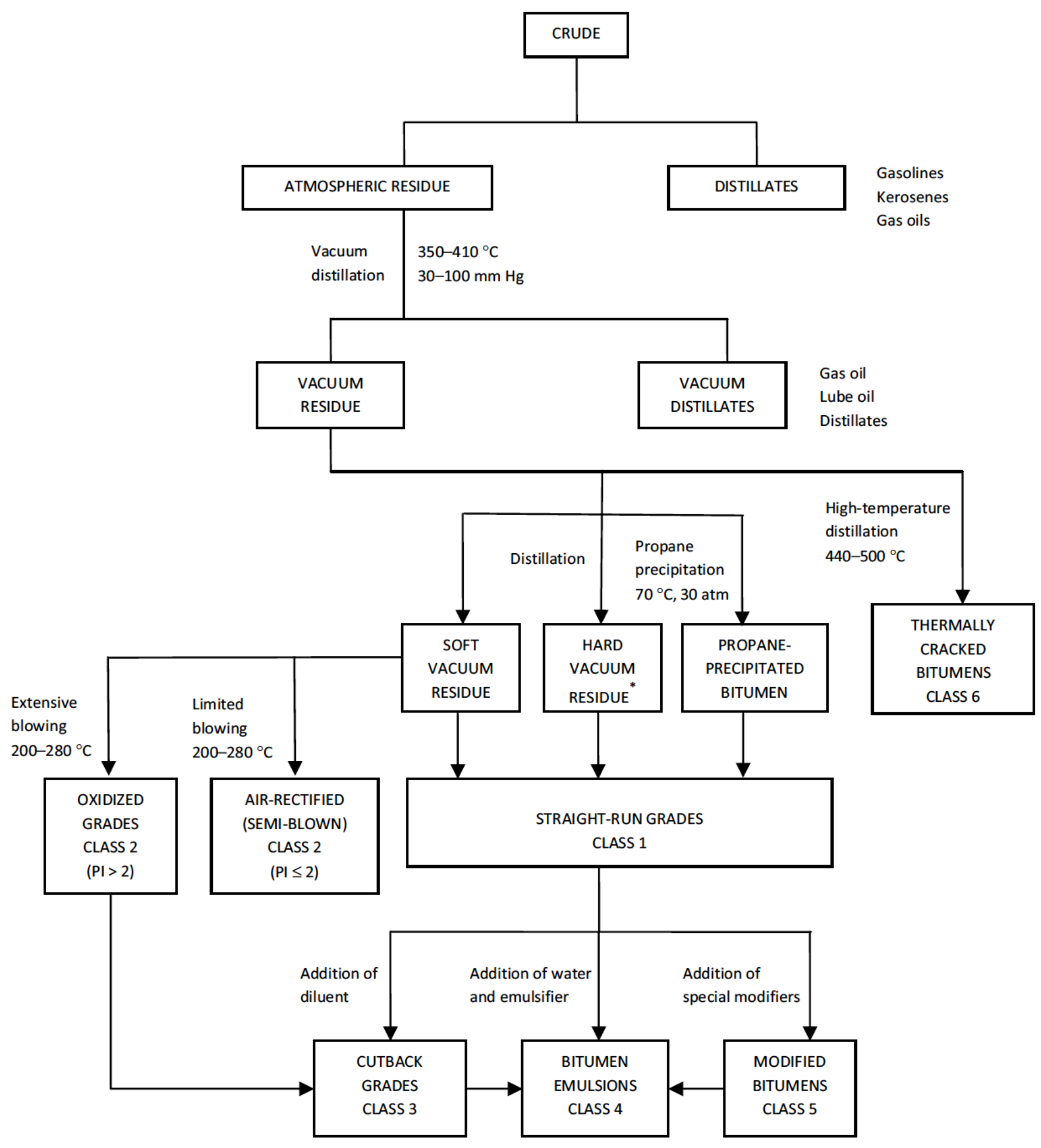

(IARC, 2013)

\subsection{Crushed Aggregate Production Flow Chart}




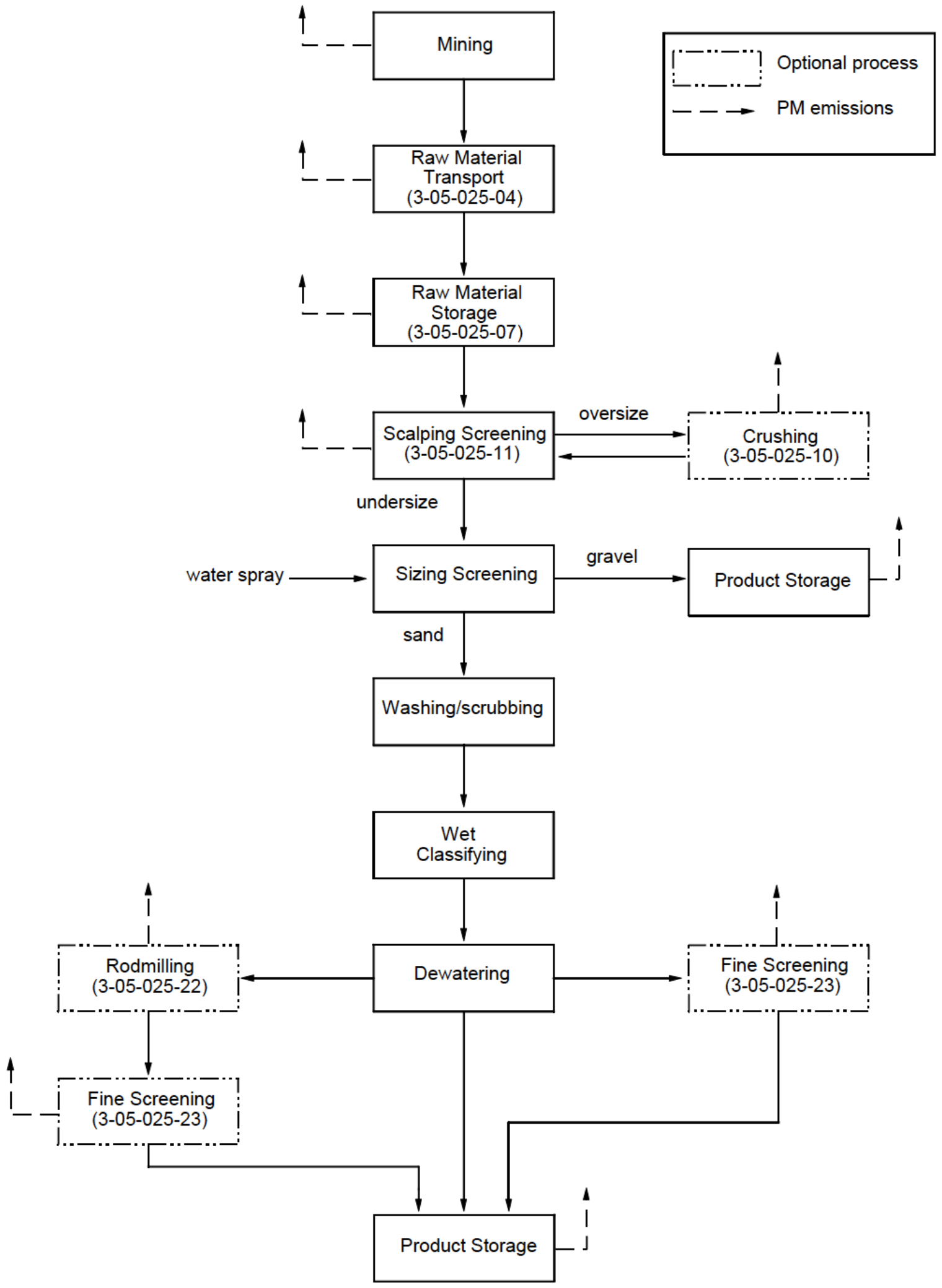

(AP 42, 2004) 


\subsection{Batch Mix Asphalt Plant Flow Diagram}

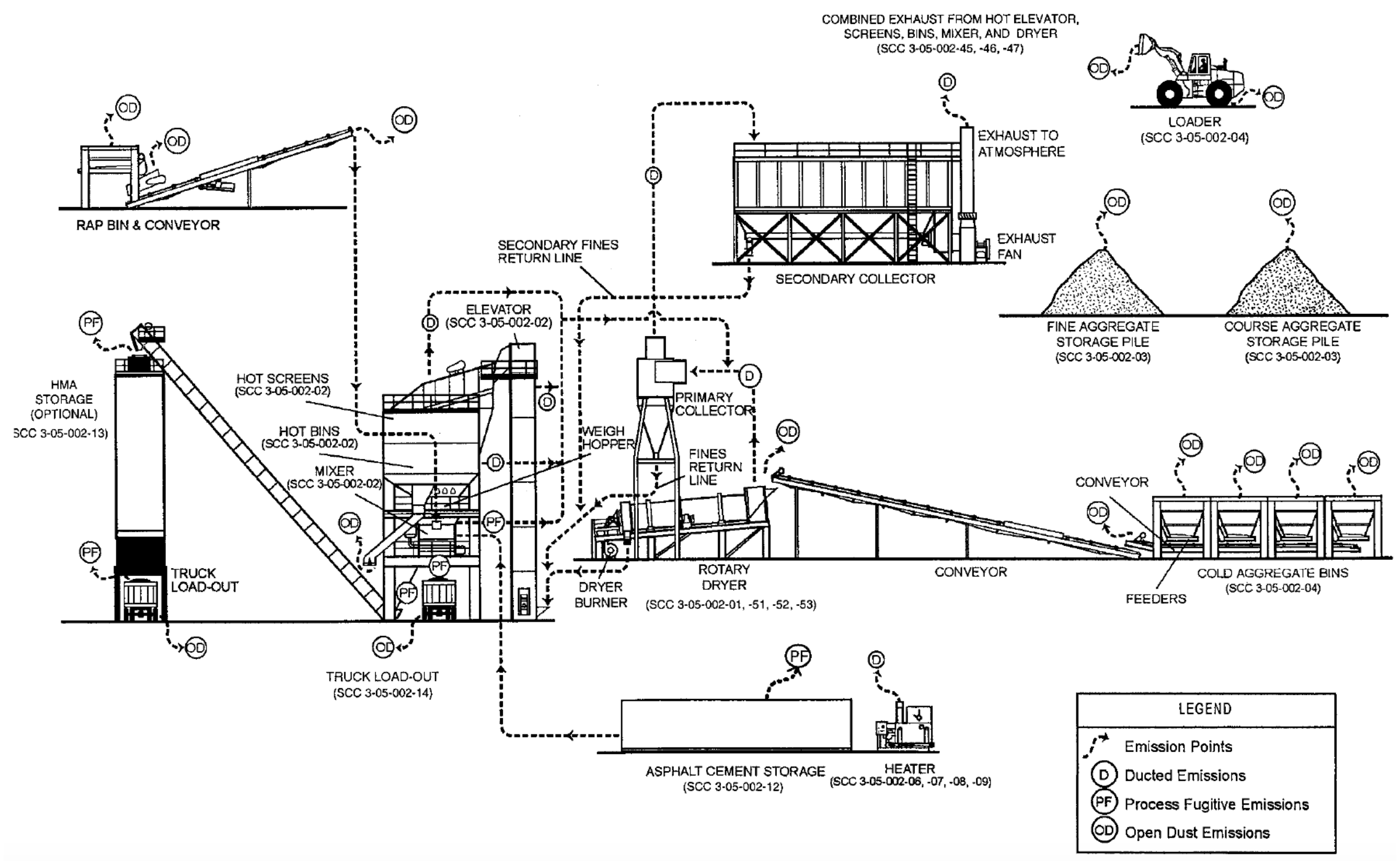

(RTI International, 2004) 


\section{4. $\quad$ Scaling Vectors Summary}

\begin{tabular}{|c|c|c|c|c|}
\hline & O\% RAP & $20 \%$ RAP & 40\% RAP & Rehabilitation \\
\hline 1 lane-km of $0 \%$ RAP HMA Pavement & $1.00 \mathrm{E}+00$ & $1.00 \mathrm{E}+00$ & $1.00 \mathrm{E}+00$ & $1.00 E+00$ \\
\hline Bitumen Production & $1.23 \mathrm{E}+02$ & $1.00 \mathrm{E}+02$ & $7.81 \mathrm{E}+01$ & $2.46 \mathrm{E}+01$ \\
\hline Bitumen Emulsion Production & $1.58 \mathrm{E}+01$ & $1.58 \mathrm{E}+01$ & $1.58 \mathrm{E}+01$ & $1.05 E+01$ \\
\hline Sand and Gravel Production & $9.93 \mathrm{E}+02$ & $7.39 \mathrm{E}+02$ & $4.84 \mathrm{E}+02$ & $1.99 E+02$ \\
\hline Crushed Stone Production & $1.12 \mathrm{E}+03$ & $9.46 \mathrm{E}+02$ & $7.77 \mathrm{E}+02$ & $2.23 \mathrm{E}+02$ \\
\hline HMA Production & $2.23 \mathrm{E}+03$ & $2.23 \mathrm{E}+03$ & $2.23 \mathrm{E}+03$ & $4.46 E+02$ \\
\hline End of Life RAP & $-2.23 E+03$ & $-3.02 \mathrm{E}+03$ & $-3.82 \mathrm{E}+03$ & $-4.46 \mathrm{E}+02$ \\
\hline $\begin{array}{l}\text { Life cycle of freight transport by a conventional diesel } \\
\text { Heavy Heavy-Duty Vocational Vehicle in } 2015\end{array}$ & $8.51 E+05$ & $8.90 E+05$ & $9.28 \mathrm{E}+05$ & $1.72 \mathrm{E}+05$ \\
\hline HMA Paving, Paver 1 & $6.96 \mathrm{E}+00$ & $6.96 \mathrm{E}+00$ & $6.96 \mathrm{E}+00$ & $1.49 E+00$ \\
\hline HMA Transfer (MTV) 1 & $6.96 \mathrm{E}+00$ & $6.96 \mathrm{E}+00$ & $6.96 \mathrm{E}+00$ & $1.49 \mathrm{E}+00$ \\
\hline Breakdown rolling, Roller 1 & $3.73 \mathrm{E}+00$ & $5.22 \mathrm{E}+00$ & $6.71 E+00$ & $7.46 \mathrm{E}-01$ \\
\hline Finish Rolling, Roller 1 & $1.86 \mathrm{E}+00$ & $1.86 \mathrm{E}+00$ & $1.86 \mathrm{E}+00$ & $6.21 \mathrm{E}-01$ \\
\hline Excavator & $2.05 \mathrm{E}+01$ & $2.46 \mathrm{E}+01$ & $2.87 E+01$ & $4.10 \mathrm{E}+00$ \\
\hline Loader & $2.05 \mathrm{E}+01$ & $2.46 \mathrm{E}+01$ & $2.87 E+01$ & $2.71 \mathrm{E}+01$ \\
\hline HMA Milling & $2.73 \mathrm{E}+00$ & $3.28 \mathrm{E}+00$ & $3.83 \mathrm{E}+00$ & $6.21 \mathrm{E}-01$ \\
\hline Conventional and LS Diesel, at fueling station & $5.81 E+02$ & $6.07 E+02$ & $6.34 \mathrm{E}+02$ & $1.17 E+02$ \\
\hline Diesel for nonroad engines & $4.46 \mathrm{E}+01$ & $5.15 \mathrm{E}+01$ & $5.84 \mathrm{E}+01$ & $2.25 \mathrm{E}+01$ \\
\hline Natural gas as a stationary fuel & $1.89 \mathrm{E}+02$ & $1.59 \mathrm{E}+02$ & $1.29 \mathrm{E}+02$ & $4.85 E+01$ \\
\hline Natural gas for electricity generation & $1.12 \mathrm{E}+03$ & $1.13 \mathrm{E}+03$ & $1.14 \mathrm{E}+03$ & $2.24 E+02$ \\
\hline Residual Oil, at POU & $3.91 \mathrm{E}+02$ & $3.27 E+02$ & $2.63 \mathrm{E}+02$ & $9.86 \mathrm{E}+01$ \\
\hline Coal to power plant & $4.25 \mathrm{E}+01$ & $3.59 \mathrm{E}+01$ & $2.92 \mathrm{E}+01$ & $1.15 E+01$ \\
\hline Electricity at POU & $3.21 \mathrm{E}+04$ & $2.97 \mathrm{E}+04$ & $2.72 \mathrm{E}+04$ & $7.20 \mathrm{E}+03$ \\
\hline
\end{tabular}




\section{5. $20 \%$ RAP and $40 \%$ RAP Impact Contributions}

\begin{tabular}{|c|c|c|c|c|c|c|c|}
\hline \multicolumn{8}{|c|}{$20 \%$ RAP } \\
\hline \multicolumn{8}{|l|}{$100 \%$} \\
\hline $90 \%$ & & & & & & & Fuel and Electricity \\
\hline $80 \%$ & & & & & & & \\
\hline $70 \%$ & & & & & & & End of Life \\
\hline $60 \%$ & & & & & & & Initial Construction \\
\hline $50 \%$ & & & & & & & - Transportation \\
\hline $40 \%$ & & & & & & & \\
\hline $30 \%$ & & & & & & & Materials Production \\
\hline $20 \%$ & & & & & & & \\
\hline $10 \%$ & & & & & & & \\
\hline \multicolumn{8}{|c|}{ g PM2.5eq } \\
\hline \multicolumn{8}{|c|}{$40 \%$ RAP } \\
\hline $100 \%$ & & & & & & & \\
\hline $90 \%$ & & & & & & & Fuel and Electricity \\
\hline $80 \%$ & & & & & & & \\
\hline $70 \%$ & & & & & & & End ot LITe \\
\hline $60 \%$ & & & & & & & Initial Construction \\
\hline $50 \%$ & & & & & & & Transportation \\
\hline $40 \%$ & & & & & & & \\
\hline $30 \%$ & & & & & & & Materials Production \\
\hline $20 \%$ & & & & & & & \\
\hline $10 \%$ & & & & & & & \\
\hline \multirow[t]{2}{*}{$0 \%$} & & & & & & & \\
\hline & Energy & g CO2eq & g SO2eq & g NOxeq & g NOxeq & g PM2.5eq & \\
\hline
\end{tabular}

